To Be Presented In Professor Fanger Jubileum Seminar on August 26-27, 2004 And Published in a Special Issue Of Indoor Air Journal

\title{
SUMMARY OF HUMAN RESPONSES TO VENTILATION
}

\author{
Olli A Seppänen \\ Helsinki University of Technology, P.O.Box 4100, FIN-02015 HUT, Finland \\ Olli.seppanen@hut.fi \\ William J Fisk \\ Indoor Environment Department,Lawrence Berkeley National Laboratory, \\ Berkeley, CA 94720, USA \\ WJFisk@LBL.GOV
}

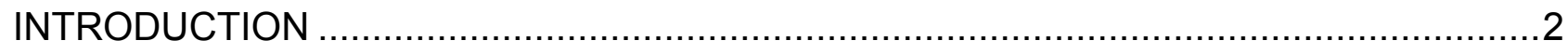

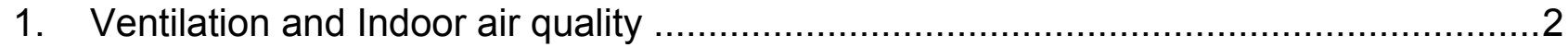

2. Role of ventilation in controlling pollutants in indoor environment ..............................

3. Ventilation rates and human responses in office environment...................................5

Ventilation and infectious diseases ..................................................................

Association of ventilation rates with SBS-symptoms in commercial and institutional

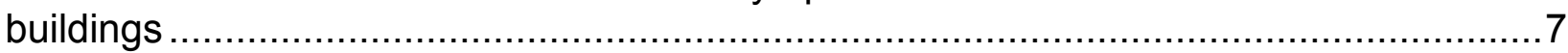

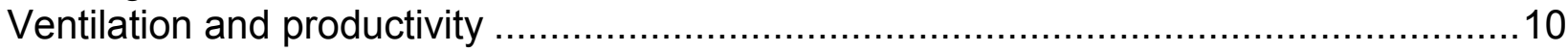

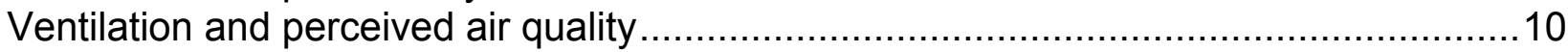

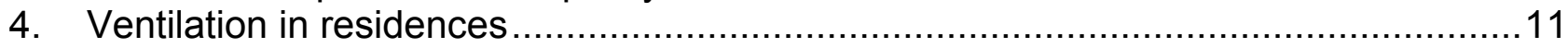

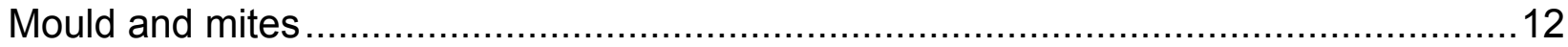

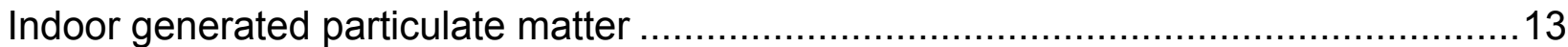

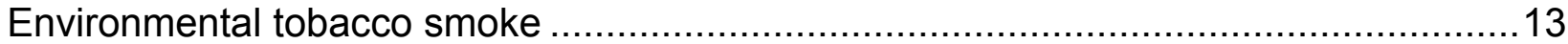

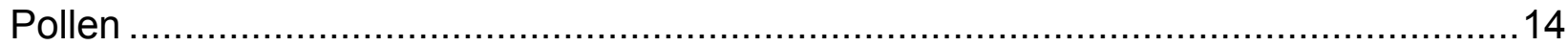

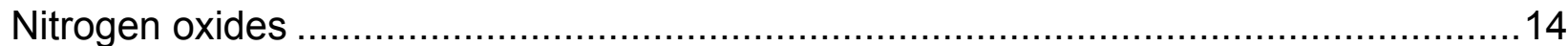

Formaldehyde and other volatile organic compounds ..........................................15

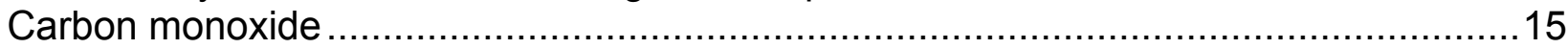

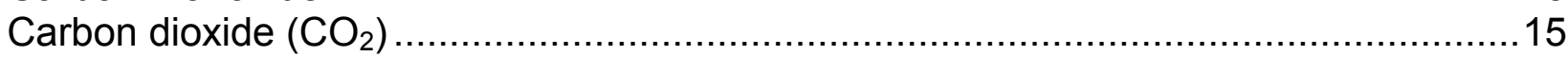

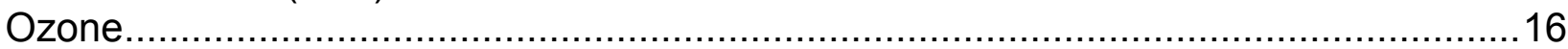

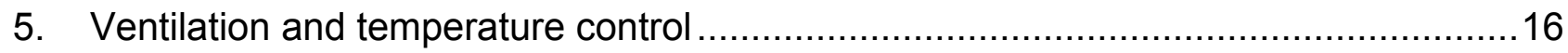

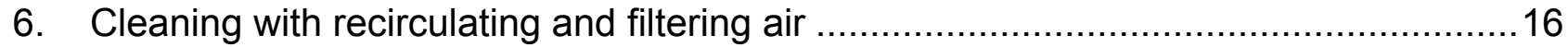

7. Association of HVAC system types with SBS symptoms ...................................17

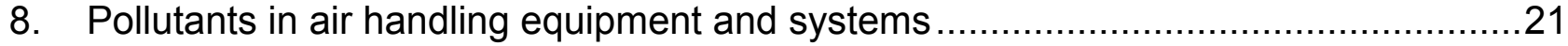

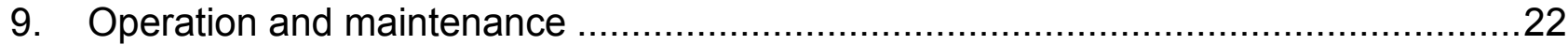

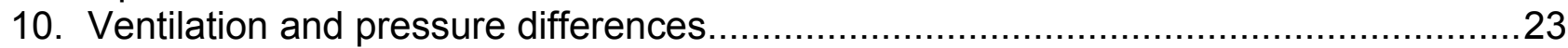

11. Summary …

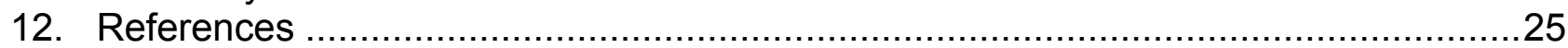




\section{INTRODUCTION}

The effects of ventilation on indoor air quality and health is a complex issue. It is known that ventilation is necessary to remove indoor generated pollutants from indoor air or dilute their concentration to acceptable levels. But, as the limit values of all pollutants are not known, the exact determination of required ventilation rates based on pollutant concentrations and associated risks is seldom possible. The selection of ventilation rates has to be based also on epidemiological research (e.g. Seppänen et al., 1999), laboratory and field experiments (e.g. CEN 1996, Wargocki et al., 2002a) and experience (e.g. ECA 2003).

Ventilation may also have harmful effects on indoor air quality and climate if not properly designed, installed, maintained and operated as summarised by Seppänen (2003). Ventilation may bring indoors harmful substances that deteriorate the indoor environment. Ventilation also affects air and moisture flow through the the building envelope and may lead to moisture problems that deteriorate the structures of the building. Ventilation changes the pressure differences over the structures of building and may cause or prevent the infiltration of pollutants from structures or adjacent spaces. Ventilation is also in many cases used to control the thermal environment or humidity in buildings.

Ventilation can be implemented with various methods which may also affect health (e.g. Seppänen and Fisk, 2002, Wargocki et al., 2002a). In non residential buildings and hot climates, ventilation is often integrated with air-conditioning which makes the operation of ventilation system more complex. As ventilation is used for many purposes its health effects are also various and complex. This paper summarises the current knowledge on positive and negative effects of ventilation on health and other human responses. The focus of the paper is on office-type working environment and residential buildings. In the industrial premises the problems of air quality are usually more complex and case specific. They are subject to occupational safety legislation and not discussed here.

\section{VENTILATION AND INDOOR AIR QUALITY}

Exposure to pollutants in indoor air may cause a variety of effects. The severity of the effects covers a wide spectrum from perception of unwanted odours to cancer. The effects may be acute or develop over longer time. Some examples of health effects related with ventilation and systems used for ventilation are (ECA 2003):

- Ventilation may dilute the concentration or disperse airborne virus or bacteria that can cause infectious diseases.

- Some micro-organisms can grow in air humidifiers and cooling towers and may result in respiratory symptoms, such as Legionnaire's disease and humidifier fever.

- Indoor humidity is influenced by ventilation rates. Very high humidity indoors is associated with an increased growth of micro-organisms such as mould and bacteria.

- Relative humidities above approximately 50\% also increases indoor dust mite levels. Ventilation may, thus, increase allergic and other type of symptoms.

- An increased risk of developing lung cancer has been linked to exposure to environmental tobacco smoke (ETS) and to radon decay products. Ventilation rates affect the indoor concentrations of ETS and radon. 
For some health effects, clear relationships with exposure to indoor air pollution have been reported. Among these are respiratory diseases (particularly amongst children), respiratory health symptoms strongly linked to building dampness problems, allergy (particularly to house dust mites and pets) and mucous membrane irritation (particularly due to formaldehyde). Large numbers of people have been, and are still affected.

Many chemicals encountered in the indoor air are known or suspected to cause sensory irritation or stimulation at least at high concentrations. As pointed out by the WHO (1989), many different sensory systems that respond to irritants have receptors situated on or near the body surface. Some of these systems tend to facilitate the response rather than habituate and their reactions are delayed. On the other hand, in the case of odour perception, the reaction is immediate but also influenced by olfactory fatigue on prolonged exposures. In general, the sensory systems are tuned towards registering environmental changes rather than the absolute levels. Sensory effects are important parameters in indoor air quality control for several reasons. They may appear as (ECA 2003):

- adverse health effects on sensory systems (e.g., environmentally-induced sensory dysfunctions)

- adverse environmental perceptions which may be adverse per se or constitute precursors of disease to come on a long term basis (e.g., annoyance reactions, triggering of hypersensitivity reactions)

- sensory warnings of exposure to harmful environmental factors (e.g., odour of toxic sulphides, mucosal irritation due to formaldehyde)

- important tools in sensory bioassays for environmental characterisation (e.g., using the odour criterion for general ventilation requirements or for screening building materials to find those with low emissions of volatile organic compounds).

It is important to realise that the sensory effects of pollutants are not necessarily linked to their toxicity. Indeed some harmful air pollutants, like radon or $\mathrm{CO}$, are not sensed at all. Therefore perceived air quality is not a universal measure of adverse effects.

Sensory effects reported to be associated with indoor air pollution are in most cases multisensory and the same perceptions or sensations may originate from different sources. Humans integrate different environmental signals to evaluate the total perceived air quality and to assess comfort or discomfort. However, it is not known how this integration occurs. Perceived air quality is, for example, mainly related to stimulation of both the nerves, trigeminus and olfactorius.

Comfort and discomfort by definition are influenced by more complex psychological factors and for this reason the related symptoms, even when severe, cannot be documented without perceptional assessments.

\section{ROLE OF VENTILATION IN CONTROLLING POLLUTANTS IN INDOOR ENVIRONMENT}

The basic steady-state equation (1) to calculate required ventilation rate for pollutant control is simple and relates the generation of pollutant, concentration differences of indoor and outdoor air, other removal mechanisms than ventilation and ventilation efficiency (modified from the equation presented in CEN 1996). 
$Q_{h}+\lambda=\frac{G_{h}}{C_{h, i}-C_{h, o}} \cdot \frac{1}{\varepsilon_{v}}$

where

$Q_{h}=$ the airflow needed for selected air quality in respect to any contaminant in the air,

$\lambda=$ the total rate of removal of the pollutant indoors by factors other than ventilation which includes deposition on surfaces, filtration, chemical reactions etc. (see also equations (3) and (4),

$G_{h}=$ the generation of contaminant,

$C_{h, i}=$ acceptable contaminant concentration in indoor air,

$C_{h, o}=$ the contaminant concentration of intake air,

$\varepsilon_{V}=$ the ventilation efficiency, $\left(\varepsilon_{V}=1\right.$ for complete mixing to $\varepsilon_{V}=2$ for ideal piston flow)

Use of the equation (1) in design means that the ventilation airflows in buildings are rationally selected and distributed to all rooms depending on the pollution loads. The problems, however, are in the application as

- the acceptable concentration of various pollutants in indoor air is not known, especially for the mixtures of hundreds of the compounds found in the indoor air

- the generation rate of pollutants indoors is not usually known

- the contaminant concentration of intake air is not known in respect of all pollutants

- the concentration of contaminants in the supply air may be different from the outdoor air due to processes in the air handling system or structures through which the supply air is flowing

- rates of pollutant removal by processes other than ventilation are poorly known

- only limited amount of information is available on the ventilation efficiency of various air distribution systems

The equation (1) can be also used to calculate required ventilation rates for moisture control or thermal control if the term for contaminant generation is replaced with moisture generation or heat generation, and concentration with moisture contents or enthalpy of the air respectively. Ventilation efficiency is dependent on the pollutant type, location and the way it is generated.

As the exact mathematical relations or threshold values for pollutants in the indoor air are not available, the information on the health effects of ventilation are in many cases based on experimental research. Parameters in the experiments may include ventilation rates, ventilation systems, contaminants in indoor air, and physical characterization of indoor environment. These factors affect human responses through each other but also independently. This is illustrated in the figure 1. Primary human responses to the ventilation which are dealt in this paper are:

- infectious diseases

- SBS-symptoms

- task performance and productivity

- perceived air quality

- allergies and asthma 
The ventilation may affect several other parameters of indoor environment which may also have health effects. These include

- thermal conditions

- effects through moisture control

- effects through the control of pressure differences

- draft (not discussed in this paper)

- noise (not discussed in this paper)

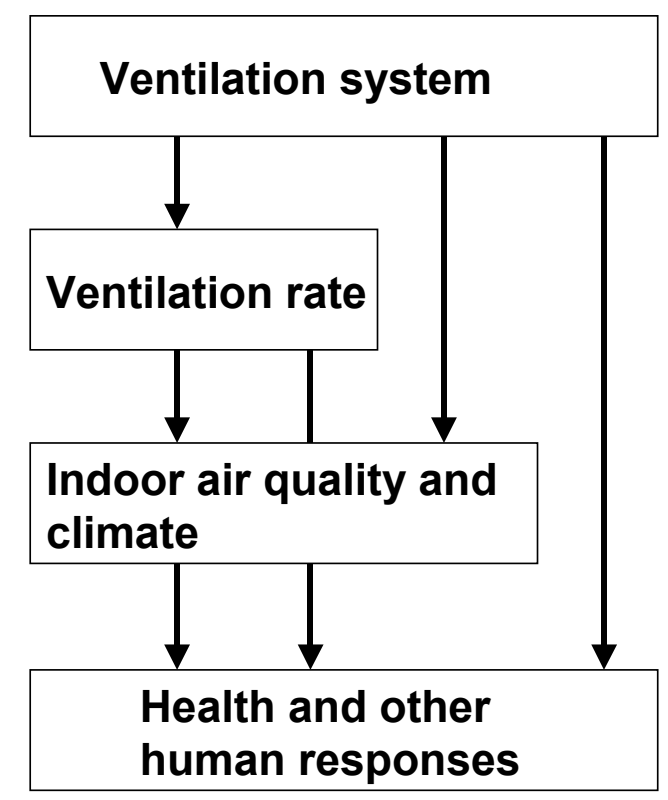

Fig 1. Ventilation affects health and other human responses through several pathways.

\section{VENTILATION RATES AND HUMAN RESPONSES IN OFFICE ENVIRONMENT}

\section{Ventilation and infectious diseases}

The review of ventilation rates and human responses (Seppänen et al., 1999) summarises the results of four studies available at that time on the health effects of ventilation rates. These were performed in a jail, barracks, a home for the elderly and offices. All of them reported significant association between low ventilation rates and increase in health problems: pneumonia, upper respiratory illnesses, influenza and short term sick leave respectively (Hoge et al.,1994, Brundage et al., 1988, Drinka et al., 1996, Milton et al., 2000). Even though the ventilation rates were estimated and not measured, the consistent findings are a strong indication of the association of ventilation rates with health effects. The strongest evidence is provided by the most recent study of these (Milton et al., 2000). The association with sick leave was analysed for 3720 employees in 40 buildings using 115 independently ventilated ventilation areas. Among office workers, the relative risk for short term sick-leave was $1.53(1.22-1.92$ c.i. $)$ with the estimated ventilation of $12 \mathrm{~L} / \mathrm{s}$ per person compared with a ventilation rate of $24 \mathrm{~L} / \mathrm{s}$ per person. Two more recent studies have been reported, with mixed results. Shendell et al. (2004) found that higher indoor $\mathrm{CO}_{2}$ concentrations (indicating less ventilation) in classrooms were associated with increased student absence, after controlling for a variety of other factors. Myatt et al. (2002) performed an experimental study in two office buildings with three month 
intervention cycles and failed to find a significant relationship between indoor $\mathrm{CO}_{2}$ concentrations and prevalence of sick leave. It is possible that Myatt's study failed to find a relationship due to the small number of buildings (2), combined with the moderate-length intervention cycles and the seasonal and episodic trends in respiratory disease.

A quantitative relationship between ventilation rate and sick leave was further developed by Fisk et al. (2003). They used Wells-Riley model (equation 2) of airborne disease transmission (Nardell et al., 1991), and fitted the data from epidemiologic studies mentioned above in it.

$$
P=\frac{D}{s}=1-\exp \left[-\frac{i p q t}{Q}\right]
$$

where

$P=$ proportion of new disease cases among the susceptible persons,

$D=$ number of new disease cases; $s=$ number of susceptible persons,

$i=$ number of infectors,

$p=$ breathing rate,

$q=$ the rate at which an infector disseminates infectious particles,

$t=$ time that infectors and susceptibles share a confined space or ventilation system,

$Q=$ rate of supply of outdoor air.

Equation (2) neglects the removal of infectious particles by filtration and by deposition on room surfaces, which are significant processes in removing airborne particles from room air. These removal processes can be expressed with effective removal rates per unit volume $n_{f}$ and $n_{d}$, yielding the equation

$$
P=\frac{D}{s}=1-\exp \left[\left(-\frac{i p q t}{V}\right) /\left(n_{v}+n_{f}+n_{d}\right)\right]
$$

where

$n_{v}=$ the ventilation rate,

$n_{f}=$ the removal rate of infectious particles by filtration, equal to the product of the

recirculation air flow rate and the filter efficiency; and

$n_{d}=$ the removal rate of particles due to deposition on room surfaces.

In this equation the term ipqt $N$ is the unknown. It was calculated from the experimental data and applied it the equation. Figure 2 plots the calculated values of illness or shortterm sick leave versus ventilation rate, normalized by the illness or sick leave rate predicted with no ventilation. All predictions show the expected decrease in illness over time; however, the rate of decrease varies dramatically for low ventilation rates, with the prediction based on the data of Drinka et al. (1996) appearing as an outlier.

For comparison to the disease transmission model, also a much simpler model was used in which the disease prevalence is proportional to reciprocal of the total infectious particle removal rate

$$
P \propto 1 /\left(n_{v}+n_{f}+n_{d}\right)
$$


This model is consistent with the assumption that the disease prevalence in the building is proportional to the indoor concentration of infectious particles. The simple particle concentration model (equation 4) provides a mid-range prediction (Fig 2).

Fisk et al. (2003) draw the conclusion: The majority of existing literature indicates that increasing ventilation rates will decrease respiratory illness and associated sick leave. A disease transmission model, calibrated with empirical data, can been used to estimate how ventilation rates affect sick leave; however, the model predictions have a high level of uncertainty.

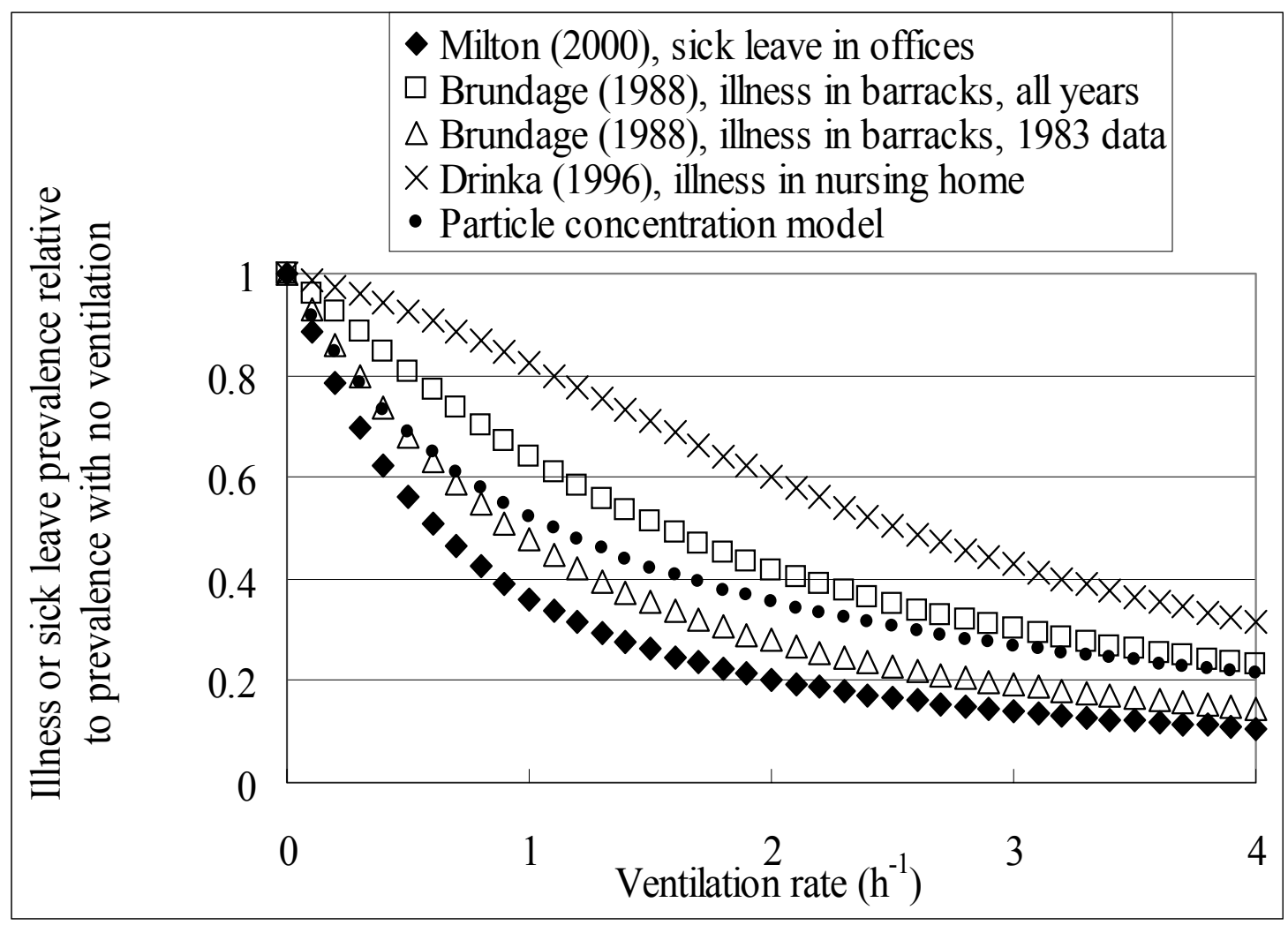

Fig 2. Predicted trends in illness of sick leave versus ventilation rate (adapted from Fisk et al., 2003)

\section{Association of ventilation rates with SBS-symptoms in commercial and institutional buildings}

Reviews by Seppänen et al. (1999) and Wargocki et al. (2002a) on the association of ventilation rates and human responses show that ventilation rates below $10 \mathrm{Ls}^{-1}$ per person are associated with a significantly worsened prevalence or value of one or more health or perceived air quality outcomes.

Seppänen et al. (1999) reviewed of current literature on the associations of ventilation rates in non-residential and non-industrial buildings (primarily offices) with health and other human outcomes. Twenty studies, with close to 30,000 subjects, investigated the association of ventilation rates with human responses, and 21 studies, with over 30,000 subjects, investigated the association of carbon dioxide concentration with these responses. Almost all studies including ventilation rates below $10 \mathrm{Ls}^{-1}$ per person found 
these ventilation rates to be associated in all building types with statistically significant worsening in one or more health or perceived air quality outcomes. Some studies determined that increases in ventilation rates above $10 \mathrm{Ls}^{-1}$ per person, up to approximately $20 \mathrm{Ls}^{-1}$ per person, were associated with further significant decreases in the prevalence of SBS symptoms or with further significant improvements in perceived air quality. The ventilation rate studies reported relative risks of $1.1-6$ for sick building syndrome symptoms for low compared to high ventilation rates.

Each assessment included in the reviewed studies with sick building symptom as outcome are presented in figure 3. The references to the papers cited in the table are provided in (Seppänen et al.,1999). When outcomes at two levels of ventilation rate are compared, each level is represented with a circle, with multiple comparisons within single studies displayed separately. If the study compared outcomes among groups of workers experiencing different ranges of ventilation rate (e.g., $<10 \mathrm{Ls}^{-1}$ per person versus $>10 \mathrm{Ls}^{-1}$ per person), the graph presents the approximate mean ventilation rate within each range. Statistically significant differences in outcomes at different ventilation rates are illustrated graphically within the table, with a shaded circle indicating at least one significantly worsened health or perception outcome at that ventilation rate. All circles being unshaded indicate lack of statistically significant increase in any outcome with ventilation. In general the criteria for statistical significance are $p<0.05$, or a $95 \%$ confidence interval that excludes unity. For each assessment, the range of relative risks (essentially the symptom prevalence at lower ventilation rate divided by symptom prevalence at higher ventilation rate) is included in the tabulated information. Several assessments treated the measured ventilation rates as a continuous variable in the statistical model used to analyze study data and the results are illustrated with shaded or unshaded horizontal bars. If the ventilation rate variable was a statistically significant parameter in the model, suggesting a dose-response relationship, the horizontal bar is shaded with the darker shading denoting more symptoms.

Almost all the studies included in the review which included ventilation rates below $10 \mathrm{Ls}^{-1}$ per person found that these rates were associated with a significantly worse prevalence or value of one or more health or perceived air quality outcomes. Most assessments included multiple statistical tests, e.g., for the association of multiple symptoms with ventilation rate, and in 25 of 34 assessments with information provided, $50 \%$ or more of the statistical tests indicated a significant association with ventilation rate. Available studies further show that increases in ventilation rates above $10 \mathrm{Ls}^{-1}$ per person, up to approximately $20 \mathrm{Ls}^{-1}$ per person, are sometimes associated with a significant decrease in the prevalence of SBS symptoms. The less consistent findings for relationships in the range above $10 \mathrm{Ls}^{-1}$ per person are compatible with the prediction that benefits per unit increase in ventilation would be likely to diminish at higher ventilation rates and, thus, be more difficult to detect epidemiologically.

However, some studies which collected outcome data at several levels or ranges of ventilation, assessed with a statistical model whether there was a dose-response relationships. Data from multiple such studies indicate a dose-response relationship between ventilation rates and health and perceived air quality outcomes, up to approximately $25 \mathrm{Ls}^{-1}$ per person; however, available data are not sufficient to quantify an average dose-response relationship. Only five studies were conducted in hot humid climates, thus, the results of this review apply primarily for moderate and cool climates. Most of these studies have been conducted in office buildings. 


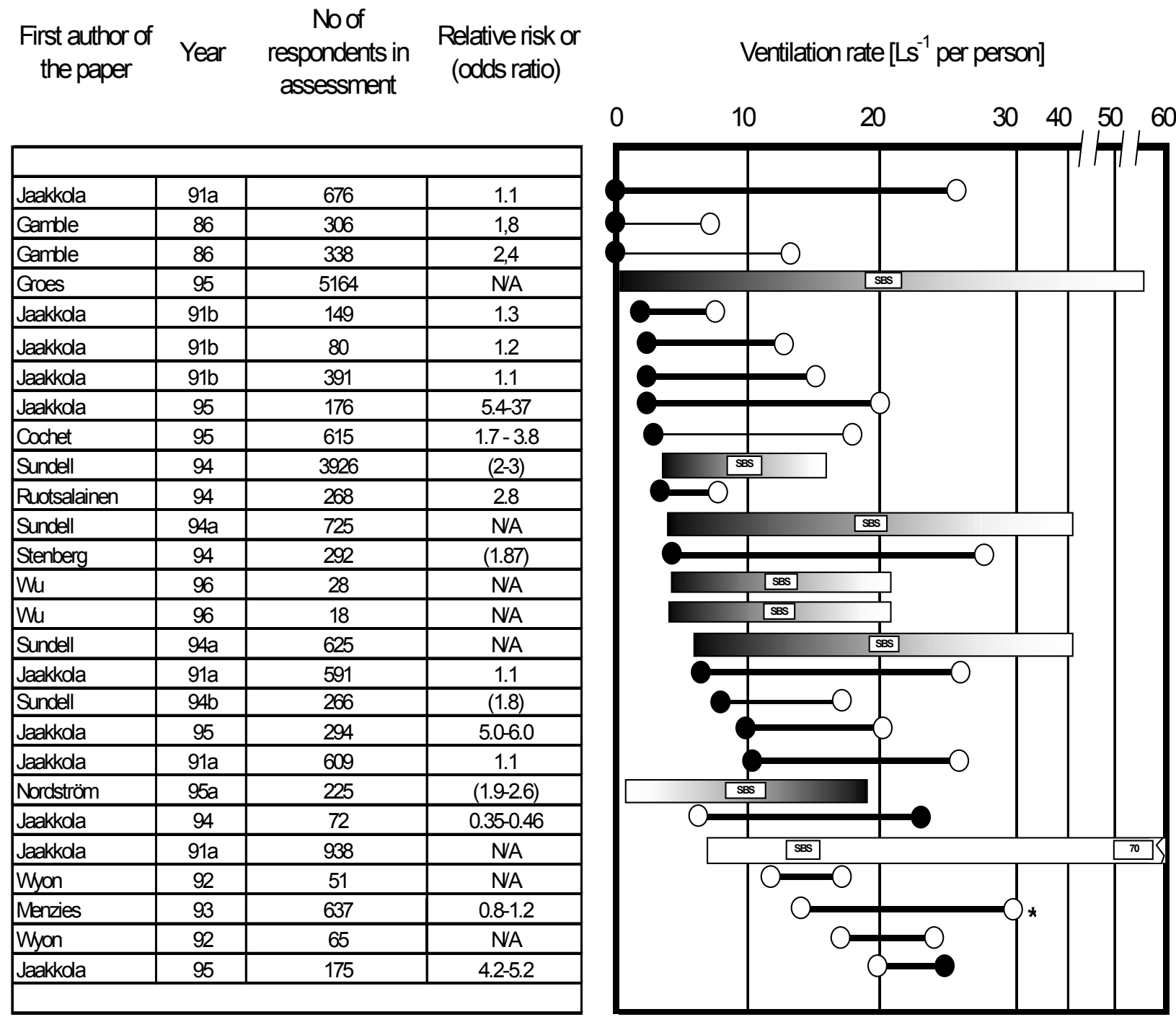

Fig 3 Summary of studies with measured ventilation rates per person, and sick building syndrom symptoms. The circles in the chart denote mean ventilation rates compared in the assessment (adapted from Seppänen et al.,1999).

Based on these results, Seppänen et al. (1999) concluded that in office buildings or similar spaces constructed using current building practices, increases in ventilation rate in the range between 0 and $10 \mathrm{Ls}^{-1}$ per person will, on average, significantly reduce occupant symptoms and improve perceived air quality. Increases in ventilation rate above $10 \mathrm{Ls}^{-1}$ per person up to $20 \mathrm{Ls}^{-1}$ per person may further reduce symptoms and improve air quality, although these benefits are currently less certain based on available data. No threshold for effects is evident at $10 \mathrm{Ls}^{-1}$ per person or at any other specific ventilation rate. As ventilation rates increase, benefits gained for occupants per additional unit of ventilation are likely to decrease in magnitude and to require larger studies for convincing demonstration. Benefits which have yet to be consistently demonstrated in this way (e.g., for ventilation rates above $10 \mathrm{Ls}^{-1}$ per person) may still be of substantial public health importance. Ventilation standards thus may need to periodically revisit the available evidence for occupant benefits at particular ventilation rates, and the magnitude of these 
benefits, weighed against the current incremental costs of increasing ventilation. This process would be new, as minimum ventilation rates in existing codes and standards do not substantially reflect health data such as is reviewed here.

Dose-response relation between measured average $\mathrm{CO}_{2}$ - concentration and several typical SBS-symptoms was reported also from the analysis of the US BASE study data (Apte et al., 2000, Erdmann et al., 2002).

The effect of ventilation on SBS-symptoms were reported also in an intervention study in tropics (Tham et al., 2003a). They reported a statistically significant reduction in intensity of headache and difficulty in concentration when ventilation was increased from 9.8 to 22.7 $\mathrm{Ls}^{-1}$ per person, and found an increase in symptom intensity when the intervention was reversed.

SBS-symptoms are also related to productivity and sick leave based on an analysis by Niemelä et al. (2003).

\section{Ventilation and productivity}

The effect of ventilation on productivity was demonstrated by Wargocki et al. (2000a) in a simulated office environment. In a room containing carpet removed from a problem building, they exposed five groups of six female subjects to three ventilation rates $(3,10$, and $30 \mathrm{Ls}^{-1}$ per person), one group and one ventilation rate at a time. The performance of four simulated office tasks improved monotonically with increasing ventilation rates, and the effect reached significance in the case of text typing. For each twofold increase in ventilation rate, performance improved on average by $1.7 \%$ in the range of $0.8-5.3 \mathrm{Ls}^{-1}$ per olf. The study indicates the benefits of ventilation at rates well above the minimum levels prescribed in existing standards and guidelines, at least when this pollutant source is present in the building.

Wargocki et al. (2003) reported that the increase of ventilation from 2.5 to $25 \mathrm{~L} / \mathrm{s}$ per person caused performance to increase as indicated by reduced average talk time $(P<0.055)$ in a call center with a new filter in the air handling system and to decrease $(P<0.05)$ with a used filter so that talk-time was about $10 \%$ lower with a new filter than with a used filter at high outdoor air supply rate.

Tham et al. (2003b) reported also that performance of office workers increased in tropics when outdoor air supply rate was increased from 9.8 to $22.7 \mathrm{Ls}^{-1}$ per person at temperature of $24.4^{\circ} \mathrm{C}$.

In a recent, non-peer reviewed, study performed within a call center in California (HMG 2003), a higher rate of outdoor air supply per unit floor area was associated with faster handling of calls. The association was significant, $p<0.10$, in a multivariate analysis that controlled for other factors. Work speed increased on average by $4 \%$ per $5 \mathrm{Ls}^{-1}$ per per square meter of floor area increase in outdoor air supply. Based on the reported peak occupancy, one can estimate a $1 \%$ increase in work speed per $10 \mathrm{Ls}^{-1}$ per person increase in outdoor air supply.

\section{Ventilation and perceived air quality}

The effect of reduced ventilation on diminished perceived air quality has been well documented. Many ventilation standards have been based on perceived air quality (e.g. 
ASHRAE 62). Perceived air quality has been related to predicted percentage of dissatisfied and acceptability of the air quality in several studies and summarized in (CEN 1996 and ECA 2003). The summary of the field measurements (Seppänen et al., 1999) on perceived air quality and ventilation rates shows also the connection (Figure 4).

In some laboratory tests with ventilation rates and pollution loads (Wargocki et al., 2000b) the perceived air quality (PAQ) has been correlated with performance. The estimated effect on performance based on typing, addition and proof reading tests was $1.1 \%$ per each $10 \%$ of dissatisfied people with air quality in the range of $25-75 \%$ of disastified. This linkage, however, may overlap with the linkage between SBS and productivity as PAQ may also be correlated with the prevalence of SBS as both are subjectively reported.
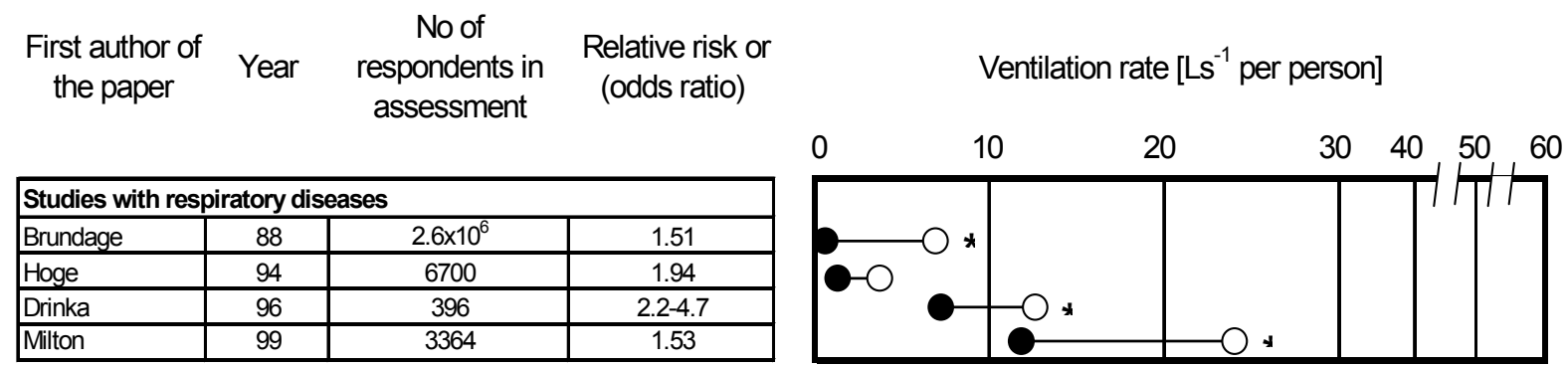

\begin{tabular}{|l|c|c|c|}
\hline \multicolumn{4}{|l|}{ Studies with respiratory diseases } \\
\hline Brundage & 88 & $2.6 \times 10^{6}$ & 1.51 \\
\hline Hoge & 94 & 6700 & 1.94 \\
\hline Drinka & 96 & 396 & $2.2-4.7$ \\
\hline Milton & 99 & 3364 & 1.53 \\
\hline
\end{tabular}

\begin{tabular}{|l|c|c|c|}
\hline \multicolumn{4}{|l|}{ Studies with percieved air quality } \\
\hline Bluyssen & $95 \mathrm{a}$ & 5164 & $\mathrm{~N} / \mathrm{A}$ \\
\hline Groes & 95 & 5164 & $\mathrm{~N} / \mathrm{A}$ \\
\hline Nordström & $95 \mathrm{~b}$ & 225 & $(03-0.4)$ \\
\hline Palonen & 90 & 580 & $1.9-2.8$ \\
\hline Ruotsalainen & 94 & 268 & 2.8 \\
\hline Cochet & 95 & 522 & $\mathrm{~N} / \mathrm{A}$ \\
\hline Zweers & 90 & 12 & $\mathrm{~N} / \mathrm{A}$ \\
\hline Jaakkola & 94 & 72 & 0.47 \\
\hline
\end{tabular}

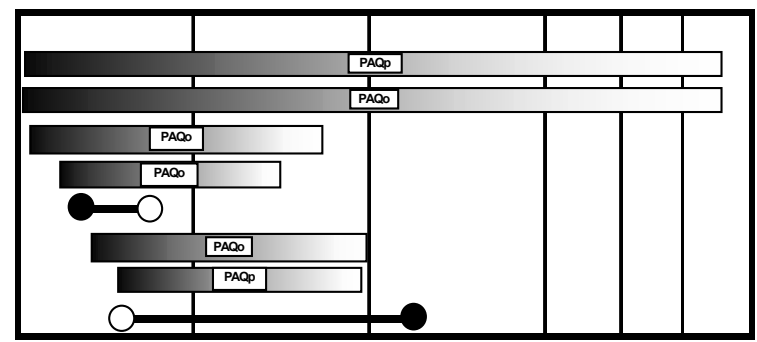

\begin{tabular}{|l|c|c|c|}
\hline Other outcomes \\
\hline Smedje & 96 & 627 & $(0.9)$ \\
\hline Wålinder & 98 & 279 & N/A \\
\hline
\end{tabular}

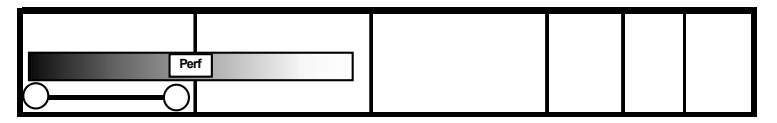

Figure 4. Summary of studies with measured ventilation rates per person, perceived air quality. The circles in the chart denote mean ventilation rates compared in the assessment. A black circle denotes a significantly worse perceived air quality. The bars denote assessments of dose response relationships. The shaded end of a bar denotes a dose-response relation between ventilation perceived air quality in the indicated ventilation range (adapted from Seppänen et al., 1999).

\section{VENTILATION IN RESIDENCES}

In residential buildings the role of ventilation to control indoor generated pollutants depends very much on the indoor sources which may vary significantly between homes. The removal of pollution sources is in general more effective way to control indoor air quality than dilute the concentration of pollutants by ventilation.

Only little information is available on the health effects of measured ventilation rates in residential buildings, however, a review by a European group (Wargocki et al., 2002a) concluded that the ventilation rates below 0.5 ach are a health risk in Nordic residential 
buildings. This conclusion was based on the ventilation necessary to maintain a low indoor relative humidity and the evidence that high humidities cause higher levels of dust mites and dust mite allergens. When the outdoor air has less moisture than indoor air, increased ventilation reduces the indoor humidity which can help prevent or reduce the indoor levels of dust mites. When it is particularly cold and dry outdoors, less ventilation is necessary for humidity control. However, in air-conditioned or dehumidified homes, ventilation is a generally source of indoor moisture because the outdoor air contains more moisture than the indoor air. In residential buildings the ventilation rates depend on air tightness of the building envelope and the ventilation system. In Nordic countries most new residential buildings use balanced ventilation with mechanical supply and exhaust of the air with heat recovery from the ventilation air. With mechanical ventilation the required ventilation rates are easily provided to each room. The drawbacks have been poor technical implementation of these systems.

Ventilation, however, affects and can control concentrations of several pollutants in residences. They are discussed in the following.

\begin{abstract}
Mould and mites
Low ventilation may lead to high indoor humidity and moisture accumulation into building structures or materials. That may lead to increased dust mites, and particularly high humidity can increase the risk of microbial growth, and subsequently to microbial contamination and other emissions in buildings. In epidemiological studies, moisture damage and microbial growth in buildings have been associated with a number of health effects including respiratory symptoms and diseases and other symptoms (Bornehag et al., 2001, Nevalainen 2002); although, the evidence of a direct link between higher air humidity levels and adverse health is quite limited. The health effects associated with moisture damage and microbial growth seem to be consistent in different climates and geographical regions (ISIAQ 1996).
\end{abstract}

It has been shown with relatively good certainty that building moisture problems and microbial growth increases the risk of respiratory symptoms. The underlying mechanisms are not well understood because the specific agents that cause the health effects have not been identified with certainty. However, particles that come from mold and bacterial contaminants are likely to be the cause of these health effects. Also toxic mechanisms may possibly be involved, especially in connection with toxin producing fungi and bacteria. Certain building materials seem to support the growth of potentially toxic microbes, and even induce toxin production more readily than other materials (Nevalainen 2002). However, it has not been conclusively demonstrated that toxins from fungi reach sufficient levels indoors to cause adverse health effects.

The primary controlling factor of the mould growth is the level of moisture within building materials. The level of moisture in materials is, in-turn, affected by the indoor relative humidity, and many other factors.

In many cases ventilation reduces the moisture contents indoors. The effect of ventilation is two fold. Ventilation can remove indoor generated moisture directly, and dilute the water content of the air to a lower level. However, when it is hot outdoors, the moisture content in the outdoor air is often higher than the indoor moisture content, because air conditioning 
and/or dehumidification systems are used to reduce indoor moisture levels. In these situations, ventilation is ineffective for indoor humidity control - in fact ventilation becomes a source of moisture and mechanical systems are needed to remove moisture from the incoming outdoor air or from recirculated air. In climatic conditions (summer in some coastal areas) the outdoor moisture contents may be high. In those conditions the ventilation is not effective.

Several studies have been performed on the effect of improved ventilation with or without dehumidification on the population of dust mites in residences (Chivato et al., 1997, Crane et al., 1998, Jones, 1999, Harving et al., 1993, Niven et al., 1999, Warner et al., 2000). Most of them have reported a reduction in the mite population but not improvement in symptoms or allergen levels. Some researchers (Howieson 2002) have pointed out the shortages in these studies. It is natural that the effect of ventilation and dehumidification is not seen in symptoms, and other human outcomes if the indoor environment is not cleaned from the accumulated allergens at the same time. The mite population generates many times more fragments of dead mites and fecal pellets that the mass of the living population. If these allergens are not removed at the same time it is obvious that the symptoms are not alleviated. In addition, in more humid climates increased ventilation may not substantially reduce indoor $\mathrm{RH}$, and, thus, have a small effect on dust mite levels. Large reductions in dust mite levels, e.g., an order of magnitude, may be necessary before substantial reductions in health effects can be detected.

\section{Indoor generated particulate matter}

Health effects of the particulate matter depend on the particle size and its composition. The particles with diameter smaller than approximately $1 \mu \mathrm{m}$ do not settle at a high rate by gravity (settling velocity about $0.15 \mathrm{~mm} / \mathrm{s}$ ) but stay air borne with air currents. The most harmful non-biological particles, in general, are thought to be those with small diameter. They penetrate deep in the lungs. Particles may carry also bacteria and virus and allergens. Many and probably most microbial particles are larger than $1 \mu \mathrm{m}$ in aerodynamic diameter, and some are much larger, e.g., > $10 \mu \mathrm{m}$ Ventilation is less effective in controlling indoor concentrations of these larger particles, because they deposit on surfaces at high rates. Particle size strongly influences the effectiveness of ventilation and filtration in controlling indoor air concentrations as discussed in (IOM 2000, Chapter 10) and Fisk et al. (2002).

The dust concentration in the air is affected also by the dust accumulated on the room surfaces from where they get air borne through the activities and air currents in the room. An effective method against exposure to dust is to keep surfaces clean and dustless. That means frequent dusting or cleaning the surfaces with effective vacuum cleaners. As the finest particles easily penetrate the dust collection reservoir of vacuum cleaner and pollutes the room air, it is important that the vacuum cleaner filters the fine particles from the air returned back to the room, or exhausts that air outdoors as is done in central vacuum cleaning systems. As the cleaning itself increases temporarily the dust concentration in the air, the cleaning should ideally be done during the unoccupied period of the space. Also adequate ventilation should be provided during the cleaning.

\section{Environmental tobacco smoke}

Extensive evidence has shown the adverse health effects of passive smoking (e.g. (California EPA 1997, 2003), including increases in lung cancer and cardiovascular 
deaths, asthma exacerbation, low birth weight, and middle ear infection. Many of the thousand compounds in the smoke are carcinogenic (Gold 1992). The size of the particles of the smoke is relative small, which makes the cleaning difficult.

The most effective method of controlling exposure to tobacco smoke is the control of smoking. It is almost impossible to control exposure to safe levels with other means in a room where smoking takes place. The control with ventilation by diluting requires very high ventilation rates. To dilute nicotine concentration of tobacco smoke to the level of $1 \mu \mathrm{g} / \mathrm{m}^{3}$, which is suggested by Finnish Institute of Occupational Health to reduce the risks of ETS to acceptable level. The criteria is based on the estimated risk of $1 / 10000$ cases of lung cancer in during 40 years' exposure based on Repace and Lowrey, (1993). To dillute nicotine concentration to this level would require require ventilation rate of $555 \mathrm{~L} / \mathrm{s}$ per a smoked cigarette in an hour if all nicotine ( typical value $2 \mathrm{mg}$ nicotine per cigarette) in the cigarette smoke is mixed with air and removed from the indoor air only by ventilation. Ventilation rates like that are impossible in practice. However, ventilation dilutes the concentration of harmful compounds of environmental tobacco smoke, and makes the air quality perceptually acceptable in short term exposure with considerably lower ventilation rates (e.g. Leaderer et al., 1983).

\section{Pollen}

Pollen is common allergen outdoors and indoors, as the pollen is carried inside with ventilation air and clothing. Pollen particles are large, often greater than $10 \mu \mathrm{m}$, and can be removed from incoming outdoor air easily with filters. Even in buildings with exhaust ventilation the filters can be installed in the air inlets. The control is easiest in the buildings with mechanical exhaust and supply ventilation, commonly used in Nordic countries. However, some plant allergens (e.g., grass and birch allergen) are present substantially in particles smaller than $1 \mu \mathrm{m}$ (e.g., Rantio-Lehtimäki et al.,1994, Schappi et al., 1997, Spieksma et al., 1990, 1991).

Room air cleaners are used to remove effectively particles from the air. Their effect on the total dose depends on their total cleaning effect. Effective cleaning air flow of those devices is the removal efficiency multiplied by the air flow through the device. The effective air flow divided by the air volume of the space to be cleaned should be more than one, and more than 2 for large particles, before the cleaning is effective. Removal efficiency of air cleaners is dependent on particle size. Small particles are more difficult to clean that large ones. Electrical air cleaners remove also the small particles from the air. Their draw back is the potential ozone generation which may be harmful.

\section{Nitrogen oxides}

Scientific evidence shows the negative health effects of exposure to nitrogen oxides (Jones 1999). Sources of nitrogen oxides are all kinds of combustion ranging from internal combustion engines to gas cooking and heating appliances. Scientific evidence shows more adverse health effects of indoor climate in the residences with open flame cooking with gas or solid fuel (Burr 2001). It is thus obvious that all open flame cooking or heating without proper chimneys or flue gas pipes should be avoided.

The use of range hoods will help some as they can capture part of the flue gases, but their typical capture efficiency is only $60 \%$, and the effectiveness is highly dependent on their proper use and cooking practice. All cooking, space heating, and water heating that can be 
done with proper control of combustion and removal of flue gases, will improve the air quality. In most cases this technology is also more cost effective than many others.

Ventilation may also cause malfunctioning of heating appliances. Exhaust ventilation may cause underpressure in an apartment or house which could cause back draft in a heating system. This should of course be avoided.

\section{Formaldehyde and other volatile organic compounds}

Material emissions have been recognized to have an influence on the total pollution load of buildings. The research and development activities in the area of material emissions started with formaldehyde emissions from particle boards about thirty years ago. The labelling schemes and quality control have greatly reduced the problem with particle boards manufactured in Europe but not with those imported from some other countries. During the last decade, research has shown that almost all materials emit chemical pollutants. Much focus has been on paints, varnishes, and flooring materials. Unfortunately the harmful emissions are not limited to the finishing materials, but include also furniture, partitions etc. In some cases, also sealants and injection putties have created problems due to high VOC emissions. Even though the emission rates of materials have significantly reduced due to labelling systems (e.g. Seppänen 2003), ventilation is needed to dilute the VOC concentrations to the acceptable levels particularly in the new and renovated buildings.

\section{Carbon monoxide}

Carbon monoxide is extremely poisonous and odourless. The source of carbon monoxide is incomplete combustion in which $\mathrm{CO}$ is generated instead of $\mathrm{CO}_{2}$. The adequate supply of air for the combustion is the method to control the generation of carbon monoxide. The most potential indoor sources of $\mathrm{CO}$ are the room heaters with gas, oil or solid fuel. Outdoor air is also a source of indoor $\mathrm{CO}$. The only practical way to control the exposure from indoor sources is the control of source, and proper use of appliances where the generation of CO is possible (Jones 1999). Indoor use of appliances with large CO emission rates these should be avoided and proper ventilation provided.

\section{Carbon dioxide $\left(\mathrm{CO}_{2}\right)$}

Indoor source of carbon dioxide is the metabolism of building occupants and pets. Outdoor concentration of $\mathrm{CO}_{2}$ is fairly constant but varies depending on the location and the time of the day. Typical outdoor air concentrations are $350-450$ ppm (parts per million i.e. $\mathrm{cm}^{3} / \mathrm{m}^{3}$ ). The indoor air concentration is dependent on the ventilation rate, and indoor sources (number of occupants). The typical indoor air concentrations of $\mathrm{CO}_{2}$ are between $500-1500$ ppm. $\mathrm{CO}_{2}$ in those concentrations is not generally thought to be harmful, it is an indicator of the concentrations of other pollutants in the air and of the ventilation rate per occupant. A recent laboratory study (Kajtár et al., 2003) suggests that human wellbeing and capacity to concentrate attention are declined when $\mathrm{CO}_{2}$ concentration in the air is increasing up to $3000 \mathrm{ppm}$.

The $\mathrm{CO}_{2}$-concentration depends on number of occupants, and duration of occupancy, ventilation rate, and room volume. As the occupancy (the generation of $\mathrm{CO}_{2}$ ) varies the concentration of $\mathrm{CO}_{2}$ is seldom constant in a building, and should be evaluated accordingly. Control of $\mathrm{CO}_{2}$ is the same as to control ventilation (Seppänen et al.,1999). 


\section{Ozone}

Ozone is an example of the pollutants with generally higher outdoor concentration than indoors. The ventilation particularly through windows will increase the ozone levels indoors and cause harmful effects. Ozone may react with the indoor generated compounds and result in more harmful compounds than the original chemicals in the reaction (Wolkoff et al., 2000)

\section{VENTILATION AND TEMPERATURE CONTROL}

Ventilation is commonly used also for temperature control. As in many countries the outdoor temperature is most of the year below indoor temperature, the ventilation can be used to reduce high room temperatures. The adverse effects of high room temperatures are well documented. High room temperature increases the prevalence of sick building syndrome symptoms, deteriorates the perceived air quality, increases the sensation of dry air in winter, and affects the performance and productivity at work (ECA 2003, Seppänen et al., 2003).

Night-time ventilative cooling in both hot and moderate climates provides an attractive opportunity for indoor temperature control with low environmental impact. Its principle is based on the daily temperature swings during hot periods. A typical daily temperature swing is around $12{ }^{\circ} \mathrm{C}$. The cool night-time air can be used to cool the building during the night, and by that way also decrease the day time temperatures.

Ventilation can also be used to increase the room air velocity, and by that way increase the convective heat transfer and decrease the thermal stress in high temperatures.

The effect of air temperature on thermal comfort is well known, but its effect on air quality is not so widely recognised. Studies have shown that warm and humid air is stuffy (BergMunch, 1980), and warm room air temperature in the winter causes a higher number of typical sick building symptoms than cooler air (Seppänen and Jaakkola, 1989). The relationship between the number of symptoms and temperature is close to linear in the temperature range from 20 to $26^{\circ} \mathrm{C}$. Laboratory experiments (Fang et al., 1998) have suggested that perceived quality of polluted air depends on the enthalpy of the air. In these tests, air was polluted with emissions from typical building materials. Studies with a whole body exposure did not show as strong effect of the enthalpy of the air on perceived air quality (Fang et al., 1997). However, the influence was still very significant. Humphreys et al. (2002) found that the thermal state of the subjects (as recorded by their comfort vote) was by far more influential than any particular characteristic of the environment (including enthalpy) in deciding perceived indoor air quality. These findings suggest the use of low room air temperature and low relative humidity in the winter from a standpoint of good IAQ and energy economy.

\section{CLEANING WITH RECIRCULATING AND FILTERING AIR}

Several types of health effects are linked to particle exposures that may be reduced via filtration. The sizes of the particles linked with these health effects vary widely. Since filter efficiency and rates of particle deposition to surfaces also vary with particle size, the concentration reductions attained from filtration, and the incremental benefits of using 
higher efficiency filters, will vary markedly with particle type. Despite the widespread use of filtration systems, the influence of different air filtration options on indoor concentrations of particles has not been well documented.

Fisk et al. (2002) used a model, and data on particle size distributions, filter efficiencies, and particle deposition rates to estimate the reductions in the indoor mass concentrations of particles attainable from use of filters in HVAC supply airstreams. Predicted reductions in cat and dust-mite allergen concentrations ranged from $20 \%$ to $60 \%$. Increasing filter efficiencies above approximately ASHRAE Dust Spot $65 \%$ did not significantly reduce predicted indoor concentrations of these allergens. For environmental tobacco smoke particles and outdoor fine mode particles, calculations indicate that relatively large, e.g., $80 \%$, decreases in indoor concentrations are attainable with practical filter efficiencies. Increasing the filter efficiency above ASHRAE Dust Spot $85 \%$ results in only modest predicted incremental decreases in indoor concentration.

\section{ASSOCIATION OF HVAC SYSTEM TYPES WITH SBS SYMPTOMS}

Summaries (Seppänen and Fisk, 2002, Wargocki et al., 2002a) showed that most studies on the association of ventilation systems and human responses indicate that relative to natural ventilation, air conditioning (with or without humidification) was consistently associated with a statistically significant increase in the prevalence by approximately $30 \%$ to $200 \%$ of one or more SBS symptoms. In two of three analyses from a single study (assessments), symptom prevalence was also significantly higher in air-conditioned buildings than in buildings with simple mechanical ventilation and no humidification. The available data also suggest, with less consistency, an increase in the risk of symptoms with simple mechanical ventilation relative to natural ventilation. The statistically significant association of mechanical ventilation and air conditioning with SBS symptoms are much more frequent than expected by chance and moreover not likely to be a consequence of being confounded by several potential personal, job, or building-related confounders. A group of European scientists (Euroven group) elaborated and tested several hypothesis on the reasons for improper performance of mechanical systems but was able to find support to some of the hypotheses only. The group concluded that potential causes of adverse health effects due to HVAC systems comprise: poor maintenance and hygiene in the HVAC systems; intermittent operation of the HVAC systems, and lack of moisture control; lack of control of HVAC system materials and loaded filters (Wargocki et al., 2002a).

The results of the review by Seppänen and Fisk (2002) are presented in the figures 5 and 6 . Figure 5 presents the assessments comparing symptoms among occupants of airconditioned buildings with those in naturally-ventilated or simple-mechanically-ventilated buildings. Figure 6 presents the assessments comparing symptoms associated with simple mechanical ventilation to symptoms associated with natural ventilation. Figures 5 and 6 provide the following data: a) the number of symptoms or symptom groups in the analyses; b) the number of symptoms that were statistically significantly associated with HVAC system type; and c) when available, the range of relative risks or odds ratios for statistically-significant associations. Additionally, the presence or absence of statisticallysignificant associations of HVAC system types with outcomes is illustrated graphically within the tables using an adaptation of the format of (Mendell, 1993). HVAC system types are indicated by circles located in the appropriate columns. When the type of humidification was uncertain or included multiple types, the circle was replaced with a 
horizontal bar extending across the applicable columns. Within these tables, shading of a circle or horizontal bar (relative to no shading), indicates that the study found a statisticallysignificant increase in prevalence of one or more symptoms among occupants with that HVAC system type relative to buildings with the reference-type of HVAC. Unshaded circles at both ends of a connecting line indicate that the subjects served by different types of HVAC systems did not have significantly different symptom prevalences. The numbers adjacent to the circles denote the number of buildings in the assessment with that type of HVAC system. Blank spaces in the tables indicate that the information was not reported.

Referring to figure 5, 16 of 17 assessments found a statistically significant increase in the prevalence of one or more symptoms with air conditioning relative to natural ventilation. Nine of these assessments controlled for two or more types of confounding factors, and eight of the nine found a significant increase in symptoms with air conditioning. Two of three assessments found a statistically significant increase in the prevalence of symptoms with air conditioning relative to simple mechanical ventilation without air conditioning; however, no significant increase in symptom prevalences was found in the assessment with the largest number of buildings. Air conditioning with or without humidification was associated with significant increases in symptom prevalences. The studies provided minimal information to assess the hypothesized increase in risks with various types of humidification. In 12 of 20 assessments, air conditioning was associated with a significant increase in the prevalence of a majority of the symptoms or symptom groups. Most of the relative risks or odds ratios were between 1.3 and 3.0 , indicating roughly up to $30 \%$ to $200 \%$ increases in symptom prevalences in the air conditioned buildings.

The results of the nine assessments that did not involve air conditioned buildings are provided in figure 6 . In five of seven assessments that compared simple mechanical ventilation to natural ventilation or to sets of buildings with both natural and exhaust ventilation, prevalences of one or more symptoms were statistically-significantly higher with simple mechanical ventilation. 


\begin{tabular}{|c|c|c|c|c|c|c|c|c|c|c|c|c|c|c|c|c|}
\hline \multirow{2}{*}{\multicolumn{2}{|c|}{ Reference }} & \multirow{2}{*}{\multicolumn{5}{|c|}{$\begin{array}{l}\text { Study and Building } \\
\text { Characteristics }\end{array}$}} & \multicolumn{8}{|c|}{ Ventilation System Type } & \multirow{2}{*}{\multicolumn{2}{|c|}{ Results }} \\
\hline & & & & & & & & \multicolumn{3}{|c|}{$\begin{array}{l}\text { Mechanical } \\
\text { Without AC }\end{array}$} & \multicolumn{4}{|c|}{$\begin{array}{c}\text { Air } \\
\text { Conditioning }\end{array}$} & & \\
\hline 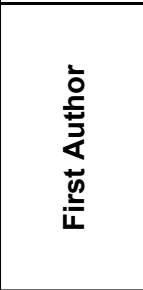 & ঠ & 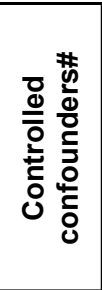 & 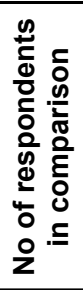 & 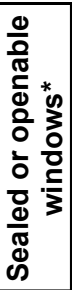 & 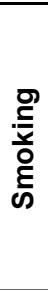 & 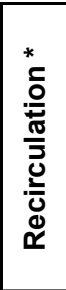 & 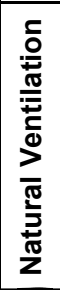 & 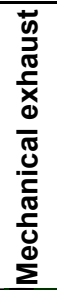 & 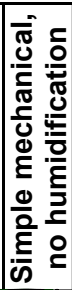 & 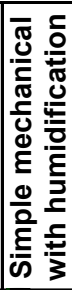 & 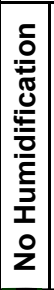 & 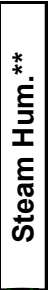 & 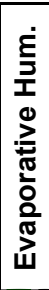 & $\begin{array}{l}\dot{\varepsilon} \\
\text { गे } \\
\text { ते } \\
\text { के } \\
\text { के }\end{array}$ & 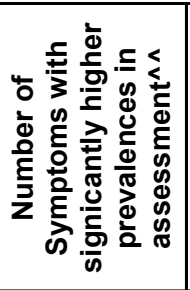 & 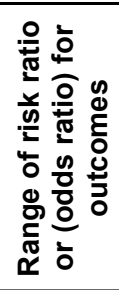 \\
\hline Jaakkola & 95 & $\mathrm{P}, \mathrm{W}, \mathrm{B}$ & 868 & $\mathrm{O}$ & & $\mathrm{Y} / \mathrm{N}$ & $7^{\mathrm{O}-}$ & & & & 9 & & & & 2 of $14 S$ & $1.5-2.6$ \\
\hline Mendell & 96 & $P, W$ & 710 & S & $\mathrm{N}$ & $\bar{Y}$ & $3^{\mathrm{O}-}$ & & & & 6 & & & & 6 of $7 \mathrm{~S}$ & $1.6-5.4$ \\
\hline Burge $^{\wedge}$ & 87 & none & 1459 & $\mathrm{~S} / \mathrm{O}$ & & & ${ }_{1} \uparrow-$ & & & & 10 & & & & 10 of $10 \mathrm{~S}$ & $(1.3-2.1)$ \\
\hline Harrison^ & 87 & none & 1044 & S & & $\mathrm{Y} / \mathrm{N}$ & $8 \mathrm{O}^{-}$ & & & & 6 & & & & 6 of $6 \mathrm{~S}$ & $(1.7-2.9)$ \\
\hline Zweers & 92 & $\mathrm{P}, \mathrm{W}, \mathrm{B}$ & 2806 & $\mathrm{~S} / \mathrm{O}$ & $\mathrm{Y}$ & & $2 \uparrow^{-}$ & & & & 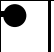 & & & & $5 \mathrm{gr}$. of $S$ & $1.5-1.7$ \\
\hline Jaakkola & 95 & $\mathrm{P}, \mathrm{W}, \mathrm{B}$ & 335 & $\mathrm{O}$ & & $Y$ & $7^{\mathrm{O}-}$ & & & & & 2 & & & 3 of $14 S$ & $(1.9-2.5)$ \\
\hline Burge $^{\wedge}$ & 87 & none & 863 & $\mathrm{~S} / \mathrm{O}$ & & & $1 \uparrow^{-}$ & & & & & 4 & & & 8 of $10 \mathrm{~s}$ & $(1.3-2.1)$ \\
\hline Zweers & 92 & $\mathrm{P}, \mathrm{W}, \mathrm{B}$ & 3573 & $\mathrm{~S} / \mathrm{O}$ & $\mathrm{Y}$ & & $21^{\mathrm{O}}$ & & & & & D & & & 5 of $5 \mathrm{gr}$. of $\mathrm{S}$ & $1.3-1.9$ \\
\hline Jaakkola & 95 & $\mathrm{P}, \mathrm{W}, \mathrm{B}$ & 559 & $\mathrm{O}$ & & $\mathrm{Y} / \mathrm{N}$ & $7{ }^{\circ}$ & & & & & & & & 3 of $14 \mathrm{~S}$ & $(2.0-2.7)$ \\
\hline Teeuw & 94 & none & 927 & $\mathrm{~S} / \mathrm{O}$ & & $\mathrm{Y} / \mathrm{N}$ & $7^{\circ}$ & & & & & & & & 5 of $8 S$ & $1.4-2$ \\
\hline Burge $^{\wedge}$ & 87 & none & 1991 & $\mathrm{~S} / \mathrm{O}$ & & & ${ }_{1} P^{-}$ & & & & & & & 15 & 10 of $10 \mathrm{~S}$ & $(1.4-2.2)$ \\
\hline Finnegan^^ & 87 & none & 787 & $S$ & $\mathrm{Y}$ & $\mathrm{Y} / \mathrm{N}$ & $3^{\circ}$ & & & & & & & 3 & 6 of $11 \mathrm{~s}$ & $(2.5-4.8)$ \\
\hline Harrison $^{\wedge}$ & 87 & none & 2080 & S & & $\mathrm{Y} / \mathrm{N}$ & $8^{\mathrm{O}-}$ & & & & & & & 3 & 5 of $6 \mathrm{~S}$ & $(2.1-3.2)$ \\
\hline Hedge $^{\wedge}$ & 84 & none & 1214 & & & & $2^{\mathrm{O}-}$ & & & & & & & 2 & 2 of $2 S$ & $(2.7-3.0)$ \\
\hline Zweers & 92 & $\mathrm{P}, \mathrm{W}, \mathrm{B}$ & 3846 & $\mathrm{~S} / \mathrm{O}$ & $\mathrm{Y}$ & & $21^{\mathrm{O}}$ & & & & & & & 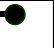 & 5 of $5 \mathrm{gr}$. of $\mathrm{S}$ & $1.5-2.1$ \\
\hline Brasche & 99 & $P, W$ & & & & & & & & & & & & & 3 of $7 \mathrm{~s}$ & $(1.4-1.4)$ \\
\hline Hawkins & 91 & $P$ & 255 & & $\mathrm{~N}$ & Y & $6^{\mathrm{O}-}$ & & & & & & & 6 & S score & \\
\hline Jaakkola & 95 & $\mathrm{P}, \mathrm{W}, \mathrm{B}$ & 1828 & $\mathrm{O}$ & & $\mathrm{Y} / \mathrm{N}$ & & & $18^{\mathrm{O}}$ & & 9 & & & & 2 of $14 \mathrm{~S}$ & $(1.3-1.7)$ \\
\hline Jaakkola & 95 & $\mathrm{P}, \mathrm{W}, \mathrm{B}$ & 1295 & $\mathrm{O}$ & & $\mathrm{Y} / \mathrm{N}$ & & & $18^{\mathrm{O}}$ & & & 2 & & & 1 of $14 \mathrm{~S}$ & $(1.8-1.8)$ \\
\hline Jaakkola & 95 & $\mathrm{P}, \mathrm{W}, \mathrm{B}$ & 1519 & $\mathrm{O}$ & & $\mathrm{Y} / \mathrm{N}$ & & & $18^{\circ}$ & & & & 3 & & & \\
\hline
\end{tabular}

$\wedge$ as reanalyzed by Mendell (1990) \#P = personal factors, $\mathrm{W}=$ work factors, $\mathrm{B}=$ building factors

${ }^{*}$ In mechanically-ventilated buildings ${ }^{* *}$ Hum $=$ Humidification ${ }^{\wedge} \mathrm{gr}=$ groups

Key:

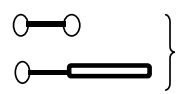

No statistically significant difference in symptoms

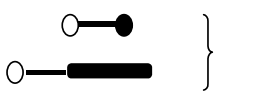

Statistically significant difference in symptoms

Fig 5. Comparison of SBS symptom prevalences with and without air conditioning (adapted from Seppänen and Fisk, 2002).

The study with the largest number of buildings (Sundell 1994) did not find a significantly higher symptom prevalence with simple mechanical ventilation; however, only ten of 540 rooms in this study had natural ventilation. In one of the five assessments (Skov et al.,1990) with increased symptoms in buildings with simple mechanical ventilation, two buildings with mechanical ventilation had humidifiers, a possible risk factor. When prevalences were significantly higher with simple mechanical ventilation, the odds ratios or relative risks ranged from 1.4 to 2.3 , with one outlier of 6.0. One of these seven assessments had the opposite finding (significantly more symptoms with natural 
ventilation) and one had no statistically-significant findings. In two other assessments in figure 6, prevalences of symptoms with mechanical exhaust ventilation did not differ significantly from prevalences with natural or simple mechanical ventilation.

\begin{tabular}{|c|c|c|c|c|c|c|c|c|c|c|c|c|}
\hline \multicolumn{2}{|c|}{ Reference } & \multicolumn{5}{|c|}{$\begin{array}{l}\text { Study and Building } \\
\text { Characteristics }\end{array}$} & \multicolumn{4}{|c|}{ Ventilation System Type } & \multicolumn{2}{|c|}{ Results } \\
\hline 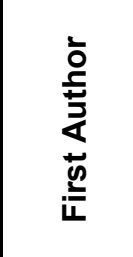 & $\stackrel{\grave{\varpi}}{\stackrel{\varpi}{\nu}}$ & 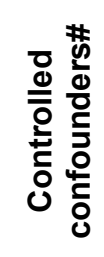 & 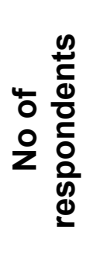 & 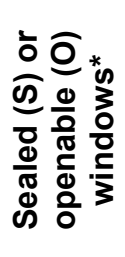 & 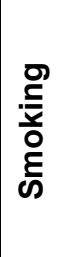 & 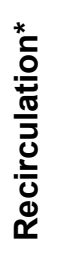 & 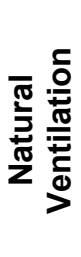 & 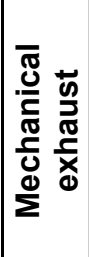 & 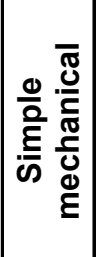 & 递 & 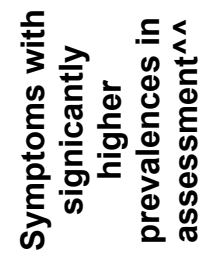 & 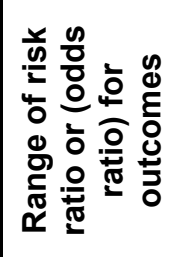 \\
\hline Jaakkola & 95 & $P, W, B$ & 456 & 0 & & $\mathrm{~N}$ & 7 & 2 & & & & \\
\hline Skov & 90 & $P, W$ & 2369 & $\mathrm{O}$ & & Y/N & 9 & & 5 & D & 2 of 2 gr. of $S$ & $1.4-1.8$ \\
\hline Jaakkola & 95 & $P, W, B$ & 1460 & 0 & & $\mathrm{Y} / \mathrm{N}$ & 7 & & 18 & & 1 of $14 \mathrm{~S}$ & 2.2 \\
\hline Mendell & 96 & $P, W$ & 300 & O & $\mathrm{N}$ & $\mathrm{Y}$ & 3 & & 3 & & 4 of $7 \mathrm{~S}$ & $1.5-5.4$ \\
\hline Burge $^{\wedge}$ & 87 & none & 1386 & $\mathrm{~S} / \mathrm{O}$ & & & 11 & & 7 & & 3 of $10 \mathrm{~s}$ & $(0.7-0.8)$ \\
\hline Sundell & 94 & $P, W, B$ & 778 & $\mathrm{~S} / \mathrm{O}$ & & & 0 & & 0 & & & \\
\hline Zweers & 92 & $P, W, B$ & 3009 & $\mathrm{~S} / \mathrm{O}$ & $\mathrm{Y}$ & & $21^{O}$ & & -0 & & $2 \mathrm{gr}$. of $S$ & $1.3-1.5$ \\
\hline Sundell & 94 & $P, W, B$ & 788 & & & & & $\mathrm{O}$ & fo & & & \\
\hline Zweers & 92 & $P, W, B$ & 2879 & $\mathrm{~S} / \mathrm{O}$ & $\mathrm{Y}$ & & 21 & & & & $4 \mathrm{gr}$. of $\mathrm{S}$ & $1.4-2.1$ \\
\hline
\end{tabular}

$\wedge$ as reanalyzed by Mendell $90 \quad \# \mathrm{P}=$ personal factos, $\mathrm{W}=$ work factors, $\mathrm{B}=$ building factors

*In mechanically-ventilated buildings $\quad{ }^{* *}$ Hum $=$ Humidification ${ }^{\wedge}$ gr. $=$ group

Key

Fig 6. Comparisons of symptom prevalences among buildings without air conditioning (adapted from Seppänen and Fisk, 2002).

The results portrayed in Figures 5 and 6 provide minimal information on the potential additional risks of humidification. Hedge et al. (1984) compared symptom prevalences among three sets of air-conditioned buildings: buildings without humidification, buildings with steam humidification, and buildings with evaporative humidification. The prevalences of five of ten symptoms differed significantly among the three HVAC types; suggesting that humidification type may affect symptom prevalences. For eight of ten symptoms, prevalences were highest with evaporative humidification. The results reported in Figure 6 of Zweers et al. (1992), comparing symptom prevalences with simple mechanical ventilation (independently with and without humidification) to symptom prevalences with natural ventilation, also suggest that humidification may be associated with higher prevalences of two out of five symptom groups. 
The reasons for the consistent increases in symptom prevalences with mechanical ventilation and particularly with air conditioning remain unclear. Multiple deficiencies in HVAC system design, construction, operation, or maintenance may contribute to the increases in symptom prevalences, including deficiencies that lead to pollutant emissions from HVAC systems. These are discussed in the next paragraph.

\section{POLLUTANTS IN AIR HANDLING EQUIPMENT AND SYSTEMS}

As reported in the previous paragraph several studies have shown that the prevalence of SBS-symptoms is often higher in air conditioned buildings than in buildings with natural ventilation. One explanation for the association of SBS symptoms and mechanical HVACsystems is VOC's and other chemical pollutants which are emitted by HVAC-components and ductworks. It has been shown that chemical and sensory emissions of building materials, ventilation systems and HVAC-components are also significant and play a major role in the perceived indoor air quality of a space (Fanger et al.,1988). The emissions may originate from any component in the HVAC-system. The measurements of chemical emission from typical materials used in HVAC-system are sparse. Measurements indicate (Morrison and Hodgson 1996, Morrison et al.,1998) that emission rates of VOC's emitted by the materials varies consierably. High emitting materials in their measurements were used duct liner, neoprene gasket, duct connector and duct sealant. The high surface area materials such as sheet metal had lower emission rates.

The European audit project on indoor air quality (Bluyssen et al., 1996), the European Data Base Project on Air Pollution Sources and the European Airless project (Bluyssen et al., 2001) have shown that the perceived quality of supply air is not always the best possible, and is often even worse than the perceived quality of outdoor air quality. The perceived air quality of the air supplied to the rooms, however, was usually not as bad as it was immediately after passing through a filter. This may be due to absorption in duct systems or chemical reactions in the air. A recent study (Wargocki et al., 2002b) has shown a slightly lower but still significant pollution load from building sources including the air handling systems $\left(0.04-0.27\right.$ olf $\left./ \mathrm{m}^{2}\right)$.

The emission of VOCs may increase when the components and surfaces get dirty due to inferior maintenance. This hypothesis is supported by several field studies which have reported the association between the indoor air problems and cleanliness of HVACsystem. Crandall et al. (1996) reported that poor HVAC cleanliness was significantly related to elevated multiple respiratory symptoms with risk ratio of $R R=1.8$, dirty filter with $R R=1.9$, debris inside air intake with $R R=3.1$, and dirty duct work with $R R=2.1$. These all are indicators of sources of chemical pollutants in the HVAC-system.

The importance of the cleanliness of air handling systems has been already recognised in the national guidelines and standards in many countries (CEN 2003, FiSIAQ 2001, ASHRAE 2001, VDI 6022 1997). A Finnish example of the cleanliness criteria of the duct system is given in the table 2 (FiSIAQ 2001). 
Table 2. The requirements of the cleanliness classification for ducts and accessories at factory. The exact instructions for sampling and analysis are determined in the protocol for testing air-handling components (Björkroth et al., 2002a, Björkroth et al., 2002b, RTS 2002).

\begin{tabular}{|c|c|}
\hline Pollutant & Criteria \\
\hline Surface density of oil in ducts ${ }^{1)}$ & $0.05 \mathrm{~g} / \mathrm{m}^{2}$ \\
\hline $\begin{array}{l}\text { Surface density of oil in accessories, terminal } \\
\text { units, and air and fire dampers }{ }^{1} \\
\text { - Parts manufactured by cutting, bending or } \\
\text { - jointing } \\
\text { - Parts manufactured from deep-drawn } \\
\text { sheet metal, processes requiring oil }\end{array}$ & $\begin{array}{l}0.05 \mathrm{~g} / \mathrm{m}^{2} \\
0.3 \mathrm{~g} / \mathrm{m}^{2}\end{array}$ \\
\hline 2) & $10^{4}$ fibers $/ \mathrm{m}^{3}$ \\
\hline Amount of surface dust & $<0.5 \mathrm{~g} / \mathrm{m}^{2}$ \\
\hline
\end{tabular}

1) The requirement is based on measurements concerning the correlation between odor intensity and the total mass of oil residuals carried out on the lubricant "Solvac". If other lubricants are used, their odor threshold will be shown to be lower than that of Solvac.

2) The concentration of mineral fibers in the air flow applies only to components which have been manufactured using materials containing fibers. The general requirements are applied to fibers other than mineral fibers.

\section{OPERATION AND MAINTENANCE}

The strength of the pollution sources may increase when the dirt accumulates. Thus the proper maintenance of the HVAC-system is important to keep components clean. There is some evidence, although limited, of a significant relation between the indicators of poor HVAC maintenance and sick building symptoms. Crandall et al. (1996) report risk ratio, $\mathrm{RR}=2.0$ between multiple lower respiratory symptoms and lack of scheduled air handler inspection in complaint buildings, and $\mathrm{RR}=2.8$ with air ductwork which has never been cleaned. However, Mendell et al. (2003a) did a more through analysis of the same data as Crandall et al. from 80 complaint office buildings, controlling for many more confounders, and only debris in the outdoor air intake and poor drainage in cooling drain pans remained significant predictors of symptoms. A similar analysis, but 100 non-complaint office buildings (Mendell et al., 2003b), found that less frequent air handler inspection was associated with increased symptoms; however, dirty cooling coils, dirty drain pans with poor drainage, and standing water near outdoor intakes were not associated with significant increases in symptoms.

Burge et al. (1990) found that low symptom buildings tend to have better operation and maintenance including manuals and instructions for the maintenance. A study in the USA (Dorgan et al.,1999) based on a survey of 96 office buildings reported a statistically significant trend between indoor air quality and level of HVAC maintenance. Specifically, as the level of system maintenance was increased (both depth and frequency), the perceived IAQ level improved. The association of SBS and improper maintenance is supported by the findings in the Swedish mandatory HVAC-inspection program (Engdahl 1998). Unsatisfactory maintenance instructions were the reason to fail the passing the inspection in more than half of the buildings with mechanical ventilation system. Angell and 
Daisey (1997) found that inferior HVAC maintenance was related in $39 \%$ of 49 schools with poor air quality.

A recent study (Menzies et al., 2003) found that irradiation of cooling coils with UV lights to reduce microbial growth on and near the coils, was associated with a significant reduction in SBS symptoms. These results suggest that microbial contamination of HVAC systems is a cause of symptoms, which implies that HVAC cleaning should be helpful. However, Menzies et al. (2003) did not find that UV irradiation reduced the measured levels of bioaerosols in the occupied space, so the reason for the symptom reduction remains uncertain.

The evidence from the epidemilogical studies and laboratory measurements support the hypothesis that contaminated HVAC-system may be source of pollutants, and increases the exposure to pollutants which increase prevalence of sick building symptoms in office buildings. There is also substantial amount of evidence that suggests neglected maintenance being a major reason to these problems. Evidence also suggests that inferior maintenance is a common problem both in North America and Europe.

Severe problems are created also with condensation if the components are not properly maintained, drained and cleaned. Improperly maintained condensing cooling coils may be a major source of microbial pollution in buildings. Several studies and guidelines (e.g. ISIAQ 1996) have pointed out the importance of the cleanliness of cooling coils. For example a study in Southern California discovered that one third of the cooling coils in the large air handling units and two thirds in the small ones were contaminated in the United States (Byrd 1996).

\section{VENTILATION AND PRESSURE DIFFERENCES}

Ventilation affects also the pressure differences over the building structures. This can be beneficial or harmful. One of the most important issues in respect of healthy buildings is to keep building structures dry and prevent the condensation in and on structures. In cold climate the water contents of the air is usually higher indoors than outdoors. If the pressure is higher indoors the air with high moisture content may flow into the cold structure and water vapour may condense and cause mould growth and other harmful effects. To decrease the risk of condensation the buildings should have higher exhaust flow rates than supply flow rates in a cold climate. This decreases the potential convection of humid indoor air to the structures. In hot humid climates, the problem is reversed, and supply air flow should be greater than the exhaust air flow.

The pressure difference may cause other harmful effects. If the pressure inside is smaller that outside the pollutants in the structures or in the other side of the structures may be drawn in. One example of this is the entry of radon into buildings from the ground in houses with basement or slab on the ground construction or poorly ventilated crawl space. This is a common problem in the buildings with exhaust ventilation built on the ground with high concentration of radon in soil gas. A similar problem is faced if the house is constructed on polluted ground such as old dump site.

Moisture damages in structure often cause the growth of mould. If the air flows through the polluted structure inside it may carry also harmful pollutants inside. It has been shown that 
the mould spores can be carried inside through a base floor in a building with mould growth in the crawl space (Airaksinen et al., 2004).

\section{SUMMARY}

As ventilation is used for many purposes its health effects are also various and complex. This paper summarises the current knowledge on positive and negative effects of ventilation on health and other human responses. The focus of the paper is on office-type working environment and residential buildings.

It is known that ventilation is necessary to remove indoor generated pollutants from indoor air or dilute their concentration to acceptable levels. But as the limit values of all pollutants are not known the exact determination of required ventilation rates based on pollutant concentrations seldom possible. The selection of ventilation rates has to be based also on epidemiological research, laboratory and field experiments and experience.

The existing literature indicates that ventilation has a significant impact on several important human outcomes including:(1) communicable respiratory illnesses; (2) sick building syndrome symptoms; (3) task performance and productivity, and (4) perceived air quality (PAQ) among occupants or sensory panels (5) respiratory allergies and asthma

In many studies, prevalence of sick building syndrome symptoms has also been associated with characteristics of HVAC- systems. On average, the prevalence of SBS symptoms is higher in air-conditioned buildings than naturally ventilated buildings. The evidence suggests that better hygiene, commissioning, operation and maintenance of air handling systems may be particularly important for reducing the negative effects of HVAC systems.

Ventilation may also have harmful effects on indoor air quality and climate if not properly designed, installed, maintained and operated. Ventilation may bring indoors harmful substances that can deteriorate the indoor environment. Ventilation interacts also with the building envelope and may deteriorate the structures of the building. Ventilation changes the pressure differences over the structures of building and may cause or prevent infiltration of pollutants from structures or adjacent spaces. Ventilation is also in many cases used to control the thermal environment or humidity in buildings.

Parameters to characterize ventilation may include ventilation rates, ventilation system types, contaminants in indoor air, and physical characterization of indoor environment. These factors affect human responses through each other but also independently.

The ventilation may affect several other parameters of indoor environment which may also have health effects. These include: thermal conditions, indoor humidity, pressure differences across the building envelope, draft, and noise.

Some conclusions on the performance of ventilation in respect of human responses:

- $\quad$ higher ventilation reduce the prevalence of air borne infectious diseases

- ventilation rates below $10 \mathrm{Ls}^{-1}$ per person are associated with a significantly worse prevalence of one or more health or perceived air quality outcomes. 
- increases in ventilation rates above $10 \mathrm{Ls}^{-1}$ per person, up to approximately $20 \mathrm{Ls}^{-1}$ per person, are associated with a significant decrease in the prevalence of SBS symptoms or with improvements in perceived air quality

- improved ventilation can improve task performance and productivity

- ventilation rates below 0.5 ach are a health risk in Nordic residential buildings

- relative to natural ventilation, air conditioning (with or without humidification) is often associated with a statistically significant increase in the prevalence of one or more SBS symptoms.

The complex relationship between ventilation rate and indoor air quality greatly complicates research on the associations of ventilation rates and systems with health outcomes, productivity and perceived air quality. Many of the epidemiological studies have failed to control for important potential confounders or have incompletely characterized the study buildings and study methods. The difficulties and inaccuracies in ventilation rate measurements have also served as a barrier to this area of research.

Limitations in existing data make it essential that future studies better assess health, productivity and PAQ changes in the ventilation rate range between 10 and $25 \mathrm{Ls}^{-1}$ per person in office-type environment. Future research should be based on well-controlled cross-sectional studies or well-designed blinded and controlled experiments. The most effective studies will include high quality measurements of ventilation rates, ample study power to detect effects considered of public health importance, and if possible, improved measures of adverse occupant outcomes; e.g., more sensitive or more objective assessment tools.

Future research, to be optimally useful for policy efforts, should increase emphasis on: dose-response relations useful for quantitative risk assessment, associations of health outcomes with ventilation rates per unit floor area (to assess the effects of pollutants from building sources as well as those from occupant source), and buildings that are not officetype environment.

A great demand is for the research on ventilation in residences, schools, and other environments with susceptible occupants: young, elderly, and not healthy people.

\section{REFERENCES}

Airaksinen M, Kurnitski J, Pasanen P, Seppänen O (2004) Fungal spore transportation through a building structure. International Journal of Indoor Environment and Health, 14, 92-104

Angell WJ, Daisey J (1997) Building factors associated with school indoor air quality problems: a perspective, Proceeding of Healthy Buildings Conference 1997, vo1 1, 143-148.

Apte M, Fisk W and Daisey J (2000). Association between indoor $\mathrm{CO}_{2}$ concentrations and sick building syndrome symptoms in U.S. office buildings: An analysis of the 1994-1996 BASE study data, Indoor Air 2000, 10: 246 - 257

ASHRAE 62. (2001) ANSI/ASHRAE standard 62-2001. Ventilation for acceptable indoor air quality. American Society of Heating Refrigerating and Air Conditioning Engineers. Atlanta.

Berg-Munch B (1980) The influence of ventilation, humidification and temperature on sensation of freshness and dryness of air. Proceedings of International Conference on Building Energy Management, Portugal.

Björkroth M, Asikainen V, Seppänen O, Säteri J (2002a) Cleanliness criteria and test procedures for cleanliness labelling system for clean ventilation products. Proceedings of Indoor Air 2002. 
Björkroth M, Seppänen O, Säteri J, Neuvonen P, Pasanen P and Railio J (2002b) Labelling system for clean ventilation components. Proceedings of Indoor Air 2002.

Bluyssen P, de Oliviera Fernandes E, Groes L, Clausen G, Fanger PO, Valbjørn O, Bernhard C, Roulet C (1996) European indoor air quality audit project in 56 office buildings. International Journal of Indoor Air Quality and Climate. 6, No. 4.

Bluyssen P, Seppänen O, Fernandes E, Clausen G, Müller B, Molina J, Roulet CA (2001) AIRLESS: A European project to optimise Indoor Air Quality and Energy consumption of HVAC-systems. In: Proceedings of CLIMA 2000, Naples.Burge, S., Jones, P. and Robertson, A. (1990) "Sick building syndrome", Proceedings of Indoor Air '90, vol 1, pp 479-484

Bornehag C-G, Blomquist G, Gyntelberg F et al. (2001) Dampness in buildings and health. Indoor Air 2001; 11:72-86.

Brundage J, Scott RM, Wayne M et al. (1988) Building -Associated Risk of Febrile Acute Respiratory Diseases in Army Trainees. JAMA. Vol. 259 (14), pp 2108- 2112

Burge S, Jones P and Robertson A (1990) "Sick building syndrome", Proceedings of Indoor Air '90, Vol 1, pp 479-484, International Conference on Indoor Air Quality and Climate.

Burr ML (2001) Combustion products. Chapter 29 in Indoor Air Quality Handbook, Spengler J.D., Samet J.M., McCarthy J.F. (editors). McGraw-Hill 2001.

Byrd R (1996) Prevalence of microbial growth in cooling coils of commercial air-conditioning systems. Proceedings of Indoor Air '96, 3: pp. 203-207, Seec Ishibashi, Inc., Japan.

California EPA (1997) Health effects of exposure to environmental tobacco smoke, Final report, September 1997. California Environmental Protection Agency, Office of Environmental Health Hazard Assessments. http://www.oehha.ca.gov/pdf/exec.pdf

California EPA (2003) Proposed identification of environmental tobacco smoke as a toxic air contaminant (Public draft). California Environmental Protection Agency, Office of Environmental Health Hazard Assessments. http://www.arb.ca.gov/toxics/ets/dreport/dreport.htm

CEN 1996. Technical report CR 1752. Ventilation for buildings: Design criteria for indoor environment. European Committee for Standardisation. Brussels.

CEN 2003. European Standard. Draft prEN 13779. Ventilation for non-residential buildings Performance requirements for ventilation and room conditioning systems

Chivato T, Montoro A, Martinez D, Gill P, Zubeldia J, De Barrio M, Baeza ML, Rubio M, Laguna R (1997) Clinical tolerance, parasitological efficacy and environmental effects of dehumidifiers in stable asthmatics sensitized to house dust mites. Allergol. et Immunopathol. 1997; 25,2: 67-72.

Crandall M, Sieber W and Malkin R (1996) HVAC and building environmentl findings and health symptoms associations in 80 office buildings, Proceedings of IAQ 1996, pp 103-108.

Crane J, Ellis I, Siebers R, Grimmet D, Lewis S, Fitzharris P (1998) A pilot study of the effect of mechanical ventilation and heat exchange on house-dust mites and Der $p 1$ in New Zealand homes. Allergy 53: 755-762.

Drinka P. Krause P. Schilling M (1996) Report of and outbreak: Nursing home architecture and influenza-A attack rates, $J$ Am Geriatric Society 44:910-913.

Dorgan CB Dorgan CE and Linder RJ (1999) The link between IAQ and maintanenc, Proceedings of IAQ and Energy, American Society of Heating, Refrigerating and Air-Conditioning Engineers, Inc., pp 47-62.

ECA (2003) European collaborative action: Urban air, indoor environment and human exposure, Ventilation, good indoor air quality and rational use of energy. Report 23.

Engdahl F (1998) Evaluation of Swedish ventilation systems. Building and Environment, Vol 33, No 4, pp 197-200.

Erdmann CA, Steiner KC, and Apte MG (2002) Indoor carbon dioxide and sick building syndrome symptoms in the BASE study revisited: analyses of the 100 building dataset. Proceedings of Indoor Air 2002, vol 3, pp 443-448. 
Fang L, Clausen G, Fanger PO (1997) Impact of temperature and humidity on the perception of indoor air quality during immediate and longer whole-body exposures. Proceedings of Healthy Buildings '97. Healthy Buildings/IAQ'97. Washington. USA. Vol 2, pp 231-236.

Fang L, Clausen G, Fanger PO (1998) Impact of temperature and humidity on the perception of indoor air quality. International Journal of Indoor Air Quality and Climate. Vol 8, No. 2., 1998

Fanger PO (1988) Introduction of the olf and the decipol units to quantify air pollution perceived by humans indoors and out doors. Energy and Buildings. No 12.

FiSIAQ (2001) Classification of Indoor Climate 2000. Espoo, Finland: Finnish Society of Indoor Air Quality and Climate (FiSIAQ), publication 5 E.

Fisk WJ, Faulkner D, Palonen J, Seppanen O (2002) Performance and costs of particle air filtration technologies. Indoor Air Journal.

Fisk WJ, Seppanen O, Faulkner D, Huang J (2003) Economizer system cost effectiveness: accounting for the influence of ventilation rate on sick leave. Proceedings of Healthy Buildings 2003, December 7 - 11 at the National University of Singapore.

Gold D (1992) Indoor air pollution. Clinics in Chest Medicine, 1992; 13: 215-229.

Harving H, Korsgaard J, Dahl R (1993) House-dust mites and associated environmental conditions in Danish homes. Allergy 48: 106-109.

Hedge A(1984) "Evidence of a relationship between office design and self-reports of ill health among office workers in the United Kingdom", Journal of Architectural Planning and Research, 1:163-174

Hoge CW, Reichler MR, Dominiguez EA et al. (1994) An epidemic pneumococcal disease in an overcrowded, inadequately ventilated jail. New England Journal of Medicine. Vol. 331 (10), pp. 643-648.

Howieson S, Lawson A, McSharry C, Morris G, McKenzie E (2002) Indoor air quality, dust mite allergens and asthma In: Levin H (ed) Proceedings of the 9 th International Conference on Indoor Air Quality and Climate, 1:113-118.

HMG (2003) Windows and offices: a study of worker performance and the indoor environment. Heschong Mahone Group, Fair Oaks, California.

Humphreys MA, Nicol JF and McCartney KJ (2002) An analysis of some subjective assessments of indoor air-quality in five European countries. Levin $\mathrm{H}(\mathrm{ed})$ Proceedings of the 9th International Conference on Indoor Air Quality and Climate 5, 86-91,

IOM (2000) Clearing the Air, Asthma and Indoor Air Quality. National Academy of Sciences, Institute of Medicine, National Academy Press, Washington, DC.

ISIAQ ( 1996). Flannigan B and Morey P. Control of moisture problems affecting biological indoor air quality. ISIAQ guideline. Task Force I. International Society of Indoor Air and Climate. Ottawa. Canada.

Jones AP (1999) Indoor air quality and health. Atmospheric Environment. 33: 4535-4564.

Kajtár L, Herczeg L, Láng E (2003) Examination of influence of $\mathrm{CO}_{2}$ concentration by scientific methods on the laboratory. In: Proceedings of Healthy Buldings Conference. Vol 3, pp 176-181. Singapore 2003.

Leaderer B, Cain W (1983) Air quality in buildings during smoking and nonsmoking occupancy. ASHRAE transactions. American society of heating, refrigerating and air-conditioning engineers, inc. pp 601-611. 1983

Mendell MJ (1993) Non-specific symptoms in office workers: a review and summary of the epidemiologic literature. International Journal of Indoor Air Quality and Climate. 3 1993:22736.

Mendell MJ, Naco GN, Wilcox TG, Seiber WK (2003a) environmental risk factors and workrelated lower respiratory symptoms in 80 office buildings; an exploratory analysis of NIOSH data. American Journal of Industrial Medicine 43:630-641. 
Mendell MJ and Cozen M (2003b) Building related symptoms among U.S. office workers and risk factors for moisture and contamination: preliminary analyses of U.S. EPA BASE data.

Lawrence Berkeley Laboratory Report, LBNL-51567, Berkeley, CA.

Menzies, D, Popa J, Hanley JA, Rand T, and Milton DK (2003) Effect of ultraviolet germicidal lights installed in office ventilation systems on workers' health and well-being: double blind multiple crossover study. The Lancet 362: 1785-1791.

Milton K, Glenross P, Walters M (2000) Risk of sick leave associated with outdoor air supply rate, humidification, and occupant complaint. International Journal of Indoor Air Quality and Climate 2000; 10:211-221

Morrison G, and Hodgson A (1996) Evaluation of ventilation system materials as sources of volatile organic compounds, Proceedings of the 7 th International Conference of Indoor Air Quality and Climate, vol 3 pp 585-590

Morrison G, Nazaroff W, Cano-Cruiz A, Hodgson A, Modera M (1998) Indoor air quality impacts of ventiation ducts: ozone removal and emissions of volatile organic compounds. Journal of the Air \& Waste Management Association, 48:941-952.

Myatt TA, Staudenmayer J, Adams K, Walters M, Wand M, Rudnick S, and Milton DK (2002) An intervention study of outdoor air supply rates and sick leave among office workers. Proceedings of Indoor Air 2002, vol. 1, pp. 778-783. Indoor Air 2002, Inc.

Nardell et al. (1991) Theoretical limits of protection achievable by building ventilation. American Review of Respiratory Disease. 144:302-306

Nevalainen A (2002) Of microbes and men. In: Levin H (ed) Proceedings of the 9 th International Conference on Indoor Air Quality and Climate, Vol 3:1-9.

Niemelä R, Seppänen O, Reijula K (2003) Prevalance of SBS-symptoms as an indicator of health and productivity in office buildings. In: Tham, Sekhar and Cheong (eds) Proceedings of Healthy Buildings Conference Singapore 2003. Vol 3: 251-256.

Niven RM, Fletcher AM, Pickering AC, Custovic A, Sivour J, Preece AR, Oldham LA, Francis H (1999)Attempting to control mite allergens with mechanical ventilation and dehumidification in British houses. Journal of Allergy \& Clinical Immunology 1999; 103: 756-762.

Rantio-Lehtimaki A, Viander M, Koivikko A (1994) Airborne birch pollen antigens in different particle sizes. Clinical and Experimental Allergy 24(1):23-28.

Repace JL, Lowrey AH. An enforceable indoor air quality standard for environmental tobacco smoke in the workplace. Risk Anal 1993: 13:463-475.

RTS. 2002. Protocol for Cleanliness Testing of Air-Handling Components. Building Information Foundation RTS. Finland. www.rts.fi.

Schappi GF, Suphioglu C, Taylor PE, Knox RB (1997) Concentrations of the major birch tree allergen Bet $\mathrm{v} 1$ in pollen and respirable fine particles in the atmosphere. Journal of Allergy and Clinical Immunology 100(5):656-661.

Seppänen O (2003) Healthy buildings- from science to practice. Plenary lecture in the International Conference of Healthy Buildings 2003. In: Proceedings of Healthy Buldings Conference. Singapore 2003.

Seppänen O and Fisk W (2002) Association of Ventilation Type with SBS symptoms in Office Workers. International Journal of Indoor Environment and Health. 12, 2:98-112.

Seppänen O, Fisk WJ, Faulkner D (2003) Cost benefit analysis of the night time-ventilative cooling in office building. In: Proceedings of Healthy Buildings 2003, vol 3 Singapore.

Seppänen OA, Fisk WJ, Mendell MJ (1999) Association of ventilation rates and $\mathrm{CO}_{2-}$ concentrations with health and other responses in commercial and institutional buildings. International Journal of Indoor Air Quality and Climate 9 1999: 252-274.

Seppänen O, and Jaakkola J (1989) Factors that may affect the results of indoor air quality studies in large office buildings. In Nagda N. and Harper, J. (eds.) Design and protocol for monitoring indoor air quality. ASTM STP 1002. 
Shendell DG, Prill R, Fisk WJ, Apte MG, Blake D, Faulkner D (2003) Associations between classroom $\mathrm{CO}_{2}$ concentrations and student attendance. Accepted for publication in Indoor Air.

Skov P, Valbjorn O, Pedersen B, and DISG (1990) Influence of indoor climate on the sick building syndrome in an office environment. Scandinavian Journal Work, Environment and Health, 16, pp. 363-371.

Spieksma FT, Kramps JA, van der Linden AC, Nikkels BH, Plomp A, Koerten HK, Dijkman JH (1990) Evidence of grass-pollen allergenic activity in the smaller micronic atmospheric aerosol fraction. Clinical and Experimental Allergy 20(3):273-280.

Spieksma FT, Kramps JA, Plomp A, Koerten HK (1991) Grass pollen allergen carried by the smaller micronic aerosol fraction. Grana 30:98-101.

Sundell J (1994) On the association between building ventilation characteristics, some indoor environmental exposures, some allergic manifestations and subjective symptom reports, Indoor Air, Supplement No. 2/94.

Tham KW, Willem HC, Sekhar SC, Wyon DP, Wargocki P, Fanger PO (2003a) The SBS-symptom and environmental perceptions of office workers in the Tropics at two air temperatures and two ventilation rates. In: Proceedings of Healthy Buildings 2003 Conference. Singapore 2003. Vol $1: 182-187$

Tham KW, Willem HC, Sekhar SC, Wyon DP, Wargocki P, Fanger PO (2003b) Temperature and ventilation effects on the work performance of office workers (study of a call center in tropics). In: Proceedings of Healthy Buildings 2003 Conference. Singapore 2003. Vol 3:280-286.

Warner JA, Frederick JM, Bryant TN, Weich C, Raw G, Hunter C, Frank R, McIntyre DA, Warner JO (2000) Mechanical ventilation and high -efficiency vacuum cleaning: A combined strategy of mite and mite allergen reduction in the control of mite-sensitive asthma. The Journal of Allergy \& Clinical Immunology 2000; 105: 75-82.

VDI 6022 (1997). Hygienic standards for ventilation and air-conditioning systems - offices and assembly rooms. VDI. Verein Deutscher Ingenieure. (Association of German Engineers).

Wargocki P, Bako-Biro Z, Clausen G, Fanger P (2002b) Air quality in a simulated office environment as a result of reducing pollution sources and increasing ventilation, Energy and buildings, 34 (20020 775-783.

Wargocki W, Sundell J, Bischof W, Brundrett G, Fanger O, Gyntelberg F, Hanssen SO, Harrison P, Pickering A, Seppänen O, Wouters P (2002a) Ventilation and health in non-industrial indoor environments. Report from a European Multidisciplinary Scientific Consensus Meeting. International Journal of Indoor Environment and Health.12:113-128.

Wargocki P, Wyon D, Fanger P (2000b) Pollution source control and ventilation improve health, comfort and productivity, In: Proceedings of Cold Climate HVAC '2000

Wargocki P, Wyon D, Fanger P (2003) Call-centre operator performance with new and used filters at two outdoor air supply rates. In: Tham, Sekhar and Cheong (eds) Proceedings of Healthy Buildings Conference Singapore 2003. Vol 3:213-218

Wargocki P, Wyon D, Sundell J, Clausen G, Fanger P (2000a) The effects of outdoor air supply rate in an office on perceived air quality, sick building syndrome (SBS) symptoms and productivity Indoor Air, Indoor Air 2000: 10:222-236

WHO (1989) Guidelines for community noise. Guideline document Edited by Birgitta Berglund Thomas Lindvall Dietrich H Schwela.

Wolkoff P, Clausen PA, Wilkins CK, Nielsen GD (2000) Formation of strong airways irritants in Terperne/Ozone mixtures. International Journal of Indoor Air Quality and Climate. 10:82-91.

Zweers T, Preller L, Brunekreef B, and Boleij JSM (1992) "Health and comfort complaints of 7043 office workers in 61 buildings in the Netherlands", Indoor Air 2(3): 127-136. 